\title{
Successful and unsuccessful attempts to swallow in a reduced Aplysia preparation regulate feeding responses and produce memory at different neural sites
}

\author{
Jeffrey M. McManus, ${ }^{1}$ Hillel J. Chiel, ${ }^{1,2,3}$ and Abraham J. Susswein ${ }^{4,5}$ \\ ${ }^{1}$ Departments of Biology, Case Western Reserve University, Cleveland, Ohio 44106-7080, USA; ${ }^{2}$ Department of Neurosciences, Case \\ Western Reserve University, Cleveland, Ohio 44106-7080, USA; ${ }^{3}$ Biomedical Engineering, Case Western Reserve University, Cleveland, \\ Ohio 44106-7080, USA; ${ }^{4}$ The Mina and Everard Goodman Faculty of Life Sciences, Bar Ilan University, Ramat Gan, 52900, Israel; ${ }^{5}$ The \\ Leslie and Susan Gonda (Goldschmied) Multidisciplinary Brain Research Center, Bar Ilan University, Ramat Gan, 52900, Israel
}

\begin{abstract}
Sensory feedback shapes ongoing behavior and may produce learning and memory. Motor responses to edible or inedible food in a reduced Aplysia preparation were examined to test how sensory feedback affects behavior and memory. Feeding patterns were initiated by applying a cholinomimetic onto the cerebral ganglion. Feedback from buccal muscles increased the response variability and response rate. Repeated application of the cholinomimetic caused decreased responses, expressed in part by lengthening protractions. Swallowing strips of "edible" food, which in intact animals induces learning that enhances ingestion, increased the response rate, and shortened the protraction length, reflecting more swallowing. Testing memory by repeating the procedure prevented the decrease in response rate observed with the cholinomimetic alone, and shortened protractions. Training with "inedible" food that in intact animals produces learning expressed by decreased responses caused lengthened protractions. Testing memory by repeating the procedure did not cause decreased responses or lengthened protractions. After training and testing with edible or inedible food, all preparations were exposed to the cholinomimetic alone. Preparations previously trained with edible food displayed memory expressed as decreased protraction length. Preparations previously trained with inedible food showed decreases in many response parameters. Memory for inedible food may arise in part via a postsynaptic decrease in response to acetylcholine released by afferents sensing food. The lack of change in response number, and in the time that responses are maintained during the two training sessions preceding application of the cholinomimetic alone suggests that memory expression may differ from behavioral changes during training.
\end{abstract}

[Supplemental material is available for this article.]

Learning and memory may be examined in intact behaving animals, and in portions of the nervous system that control the relevant behaviors. Examining intact animals may not provide access to the cellular events underlying the changes in behavior and examining plasticity in isolated tissues does not provide simultaneous monitoring of the behavioral changes arising from cellular changes. Reduced preparations that contain effectors of behavior, as well as portions of the nervous system that control the effectors, can provide a bridge between behavioral and cellular analyses (Chiel et al. 1986; Weiss et al. 1986; Cohen et al. 1997; Frost et al. 1997; Antonov et al. 2010). Such preparations may allow deeper characterization of behavioral changes that may not be evident in an intact animal, as well as providing insight into some of the underlying cellular events.

In addition to information on learning and memory, a reduced preparation may also provide an important bridge for studying how a central pattern generator (CPG) is modulated. In behaving animals, many cyclical patterns of neural activity are only intermittently truly cyclical, since they are continuously modulated. Sources of modulation include feedback from effectors of behaviors produced by the cyclical neural activity (Pearson 2004; Rossignol et al. 2006), feed-forward and feedback information from the current environment (Chiel and Beer 1997), and in-

\section{Corresponding author: avy@biu.ac.il}

Article is online at http://www.learnmem.org/cgi/doi/10.1101//m.048983.118. formation about the current state of the organism (Burke 1999). Learning and memory arising from previous experiences that are relevant to the cyclical neural activity may also influence it. Nonetheless, when portions of the nervous system that generate aspects of a repetitive behavior are examined in the absence of such influences, cyclic neural activity may be quite robust and repetitive, due to the unmodulated activity of the CPG (Marder and Bucher 2001). As progressively more information about ongoing and previous performance of the behavior is present, the output may become less influenced purely by the CPG (Diehl et al. 2013; Wenning et al. 2014; Hamood and Marder 2015).

In this article, we have examined modulation of neural activity by feedback from effectors in a reduced preparation, in which the ganglia producing cyclical activity remain attached to key effectors, the buccal musculature. This allowed us to challenge the motor system with natural loads that modify neural patterns and produce changes in behavior. Because the loads used to examine change in behavior are also stimuli used in associative learning tasks in intact animals (Susswein et al. 1986; Nargeot et al. 2007),

(C) 2019 McManus et al. This article is distributed exclusively by Cold Spring Harbor Laboratory Press for the first 12 months after the full-issue publication date (see http://learnmem.cshlp.org/site/misc/terms.xhtml). After 12 months, it is available under a Creative Commons License (Attribution-NonCommercial 4.0 International), as described at http://creativecommons.org/licenses/by-nc/ $4.0 \%$. 
the study also provides deep insight into behavioral changes that occur while animals learn, and also into the neural mechanisms producing learning and memory.

The study focuses on the consummatory phase of Aplysia feeding, which is controlled by a CPG in the buccal ganglia that organizes repetitive protractions and retractions of the toothed radula via the actions of buccal muscles (for reviews, see Elliott and Susswein 2002; Cropper et al. 2004; Wentzell et al. 2009). Activity of the CPG, and repetitive protraction and retraction movements, are central components of a number of distinct consummatory behaviors (Kupfermann 1974a; Jing and Weiss 2005; Ye et al. 2006a,b; Neustadter et al. 2007; McManus et al. 2014; $\mathrm{Wu}$ et al. 2014). In intact animals, the repetitive activity produced by the CPG shows considerable cycle-to-cycle variability (Brezina et al. 2006). The CPG is active even in an isolated buccal ganglia preparation. Activation of the CPG induces fictive feeding that can be monitored by recordings from peripheral nerves which in vivo innervate the buccal muscles effecting feeding behaviors (Morton and Chiel 1993; Susswein et al. 1996; Jing and Weiss 2001; Neveu et al. 2017). The cellular processes underlying the properties of individual CPG elements can be readily studied in an isolated ganglion preparation (Susswein and Byrne 1988; Hurwitz et al. 1994, 1997, 2008; Hurwitz and Susswein 1996; Dembrow et al. 2003; Sasaki et al. 2007; Saada et al. 2009), in which the ganglia controlling feeding are removed from the animals and studied in vitro. However, information that can be gained in isolated ganglia is limited, since one cannot examine modulation arising as a result of changes in the load that animals work against when they attempt to eat a food or learning and memory that result from successful or failed attempts to eat a food. To determine how changes in load, and learning and memory, affect the expression of fictive feeding, we have examined feeding motor patterns expressed in a reduced preparation in which the buccal ganglia remain attached to the buccal muscles, and fictive feeding is expressed both via patterns of neural activity and via observable protractions and retractions of the radula (McManus et al. 2012).

In the preparation used, the buccal ganglia and the attached buccal muscles are suspended in a saline bath. The buccal ganglia also remain attached to the cerebral ganglion, which contains a small population of command-like neurons (CBIs-cerebral-buccal interneurons-Rosen et al. 1991; Hurwitz et al. 1999, 2003; Jing and Weiss 2001, 2005; Wu et al. 2014) which can directly and indirectly activate the CPG (Jing and Weiss 2001; Hurwitz et al. 2003). Treating the cerebral ganglion with a cholinomimetic activates fictive feeding (Susswein et al. 1996), presumably because sensory neurons that respond to food are cholinergic, and acetylcholine (ACh) depolarizes and fires some of the command-like neurons (Susswein et al. 1996). Because the buccal muscles produce radula protraction and retraction, and also opening and closing of the mouth, food can be put into the buccal cavity, thereby loading the motor system. Both strips of soft, edible food, which weakly load the muscles and can be successfully swallowed, as well as food that is made inedible by wrapping it in plastic netting, which load the muscle more strongly as animals attempt to swallow it, can be placed within the mouth, thereby allowing us to examine the possible effects of different levels of loading on the behavior.

In intact animals, both successful swallowing of food and failed attempts to swallow a tough food are experiences that lead to learned changes in behavior while the animals attempt to consume the food, and subsequent changes in response when animals are again challenged with the food, reflecting memory of the previous experience (Susswein et al. 1986; Chiel and Susswein 1993; Nargeot et al. 1997, 1999, 2007; Lechner et al. 2000; Brembs et al. 2002). We tested possible changes in response during the initial exposures to the edible and inedible foods. We also tested short-term memory by reexposing the preparations to both edible and inedible foods, as well as to the cholinomimetic alone.

The presence of the peripheral musculature enriched the expression of consummatory behaviors elicited by the cholinomimetic by increasing the peak frequency, and by causing a wider variety of motor responses. Feedback from successful food consumption enhanced some aspects of feeding responses, and the enhancements were retained when the preparations were tested for a second time with food that is successfully consumed. In contrast, unsuccessful attempts to swallow food produced relatively few changes in response during either an initial attempt, or during a second attempt to consume the food. However, training with inedible food caused short-term memory that was expressed as a decrease in response to a subsequent exposure to the cholinomimetic alone.

These findings suggest different sites of memory formation in response to the different types of training. For "edible" food, aspects of short-term memory are likely to be localized to the buccal ganglia. For "inedible" food, the memory measured in the reduced preparation arises primarily via a postsynaptic decrease in response to ACh in cholinoceptive cerebral ganglion neurons. Previous work (Susswein et al. 1996) showed that lip receptors responding to food are cholinergic. Different populations of taste receptors will synapse at different postsynaptic sites. A postsynaptic decrease in response to ACh can account for food-specific learning that food is inedible.

\section{Results}

Our aim was to use a reduced Aplysia feeding preparation to provide insight into how the presence of peripheral musculature affects repetitive motor programs, and how both effective and ineffective loads (effective and ineffective attempts to consume food) modify feeding motor activity. Since both effective and ineffective attempts to swallow food lead to learning and memory that the food is edible or inedible in intact animals (Susswein et al. 1986; Nargeot et al. 1997, 1999, 2007), these studies also provide insight into how aspects of a training paradigm in a reduced preparation may affect behavior during training, and also produce short-term memory after the training. We used a suspended buccal mass preparation (McManus et al. 2012, 2014) to examine these questions. In this preparation, the buccal mass is suspended in Aplysia saline, while it remains attached to the buccal and cerebral ganglia. The buccal muscles and buccal mass are in the same chamber. The cerebral ganglion is in a separate chamber, allowing the two ganglia to be bathed in different fluids, and allowing drugs to be applied separately to the two ganglia. The buccal and cerebral ganglion are connected to one another via the cerebral-buccal connectives, which span the partition separating the two chambers.

In intact animals, the lips are stimulated with food to initiate feeding responses (Kupfermann 1974a). Because the lips are not present in the suspended buccal mass preparation, lip stimulation with food cannot be used to induce bites and food entry into the buccal cavity. To initiate motor activity, the cerebral ganglion is treated with the nonhydrolyzable cholinergic agonist carbamyl choline (carbachol-CCh) (Brown and Laiken 2011), which induces repetitive bite-like motor programs in the buccal ganglia (Susswein et al. 1996). In the suspended buccal mass preparation, because the buccal muscles are present, the mouth opens and closes, the radula protracts and retracts, and the radula halves open and close, as in intact animals (Kupfermann 1974a; Neustadter et al. 2002). Swallowing and rejection responses can be elicited, respectively, by placing into the buccal cavity either strips of seaweed, or inedible objects. Neural correlates of biting, swallowing and rejection can be examined in detail, providing insight into how the 
three behaviors are organized (McManus et al. 2012, 2014). To observe how edible or inedible foods might modulate motor programs, strips of edible food, or of an inedible food similar to that used previously to train animals (Susswein et al. 1986), were placed within the buccal cavity when the mouth opened in response to the $\mathrm{CCh}$. Video recordings of the buccal mass, and extracellular voltage recordings from the buccal nerves and from the I 2 buccal muscle, allowed us to monitor motor programs in response to the CCh and in response to the food stimuli. In addition to being initiated by CCh rather than by lip stimulation, feeding responses using inedible food in the preparation differed in a second way from that in intact animals. In the intact animal, after food enters the buccal cavity, the food may intermittently leave the buccal cavity. Because food is still in contact with the lips, additional bouts of bites and attempts to swallow are induced. During the latter portion of a training trial with inedible food, the animals become relatively unresponsive to food, and the food spends relatively little time within the buccal cavity (Susswein et al. 1986). In contrast, in the suspended buccal mass preparation the food was not permitted to exit from the buccal cavity. Whenever the food began to leave the buccal cavity, it was pushed back in.

\section{Modulation of motor program patterning by the presence of the buccal musculature}

A previous report (Susswein et al. 1996) examined parameters of motor programs elicited in response to CCh administered to the cerebral ganglion in preparations in which the cerebral and buccal ganglia did not remain attached to the buccal muscles. After an initial warm-up period, it was found that motor programs were elicited at a rate of approximately three per minute, and that $95 \%$ of the programs were bite-like, on the basis of patterns of firing recorded from buccal ganglion nerves (Morton and Chiel 1993). In addition, activity during protraction and retraction were relatively consistent, with very little variability from burst to burst, and with Radula Nerve activity marking radula closing consistently overlapping retraction. To test whether proprioceptive feedback from the muscles may affect motor activity, we examined motor programs elicited in the suspended buccal mass preparation (Fig. 1). The presence of the buccal muscles led to an increase in the peak frequency (Figs. 1, 2C,E) as well as increases in variability of the relative lengths of neural activity marking the protraction and retraction phases of motor programs (Fig. 1B). In addition, Radula Nerve activity, which is an indicator of radula closing (Morton and Chiel 1993), sometimes overlaps with protraction and sometimes overlaps with retraction (Fig. 1B).

On the basis of patterns of firing recorded from buccal ganglion nerves, feeding motor programs have been classified (Morton and Chiel 1993) as ingestion-like (either bite-like or swallow-like), rejection-like, or intermediate, primarily based on the phasing of neural activity that is a correlate of radula closing with either protraction or retraction. Classification of motor patterns based on buccal nerve recordings have been used extensively in previous reports (Morton and Chiel 1993; Susswein et al. 1996; Jing and Weiss 2001, 2005; Wu et al. 2014; Cullins et al. 2015; Neveu et al. 2017). However, recent recordings of neural activity while observing the behavior of intact animals have shown that the neural correlates are only approximate indicators of feeding behavior, with many ingestion and rejection behaviors not conforming to the patterns of activity that have been used to classify patterns in reduced preparations (Cullins 2014). For this reason, we did not attempt to assign labels of behavioral categories to the patterns of activity that were recorded. Nonetheless, differences in the activity patterns between preparations with and without the buccal muscles attached were clear (Fig 1). The heterogeneity of the responses elicited by CCh in the suspended buccal mass preparation is likely to be a closer
Comparison of Motor Patterns with and without Proprioceptive Feedback

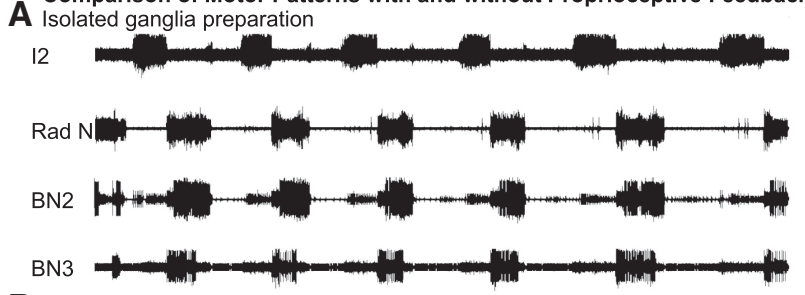

B Suspended buccal mass preparation

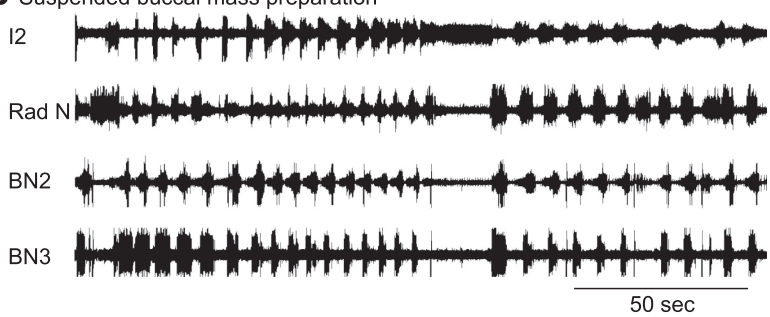

Figure 1. Changes in patterning of feeding responses as a result of the buccal mass remaining attached to the buccal and cerebral ganglia. Examples of fictive feeding induced by $\mathrm{CCh}$ applied to the cerebral ganglion in: $(A)$ a preparation in which the buccal muscles were not present, and $(B)$ a preparation in which the buccal muscles remained attached to the buccal ganglia. The records shown are portions of longer recordings, and were chosen to display the patterning and rate of responses during a $200 \mathrm{sec}$ interval at the peak of responses to CCh $(A-200-400 \mathrm{sec}$ after application of CCh; $B-270-470$ sec after application of CCh). (I2) EMG recordings from the 12 muscle, (Rad $N$ ) recording from the Radula Nerve, (BN2) recording from the right Buccal Nerve 2, (BN3) recording from the right Buccal Nerve 3. In addition to an increase in the rate at which CCh generates fictive feeding, attachment of the muscle also increases the variability of the feeding bursts that are elicited. In the isolated ganglia, note the relatively fixed lengths of 12 and BN2 bursts, which mark protraction and retraction phases, respectively, and the overlap between Rad activity and BN2, which has been used as an indicator of ingestion activity. By contrast, when the muscle is attached, note the variability in the lengths of 12 and BN2 activities, and the change in the position of Rad activity from an overlap with 12 in the first half of the record to an overlap with BN2 in the latter half.

fit to aspects of feeding behavior in intact animals than is the homogeneity of responses in the absence of the muscles. Intact Aplysia eat a variety of complex natural foods of different shapes (Kupfermann and Carew 1974; Susswein et al. 1984a) that induce a combination of different feeding behaviors (Kupfermann 1974a). The varied feeding behaviors produced by the buccal muscles are appropriate to the different types of foods eaten. Thus, food on the lips elicits bites, whereas food within the mouth elicits swallows, rejections, or intermediate responses. Complex foods elicit complex sequences of different feeding behaviors. The presence of muscles seems to enrich the programs elicited by CCh, so that their frequency becomes more similar to that in intact animals challenged with natural foods, and the types of patterns elicited become more varied.

We quantified a number of parameters of motor programs in preparations in which ganglia remained attached to the buccal muscles and in which the muscles were removed. The total number of feeding programs elicited by the CCh (Fig. 2A), and the total time that feeding programs were maintained (Fig. 2B) were similar in the two types of preparations. However, the peak frequency of the programs was higher with the muscles attached (Fig. 2C), indicating that proprioceptive feedback from the muscles increases the peak frequency, as seen in Figure 1. Nonetheless, even with the muscles attached the peak frequency was lower than in intact, hungry, fully aroused animals, in which the peak bite frequency is approximately 12 bites per minute (Susswein et al. 1976), rather than the mean of 7.03 responses per minute in the suspended buccal mass preparation. 


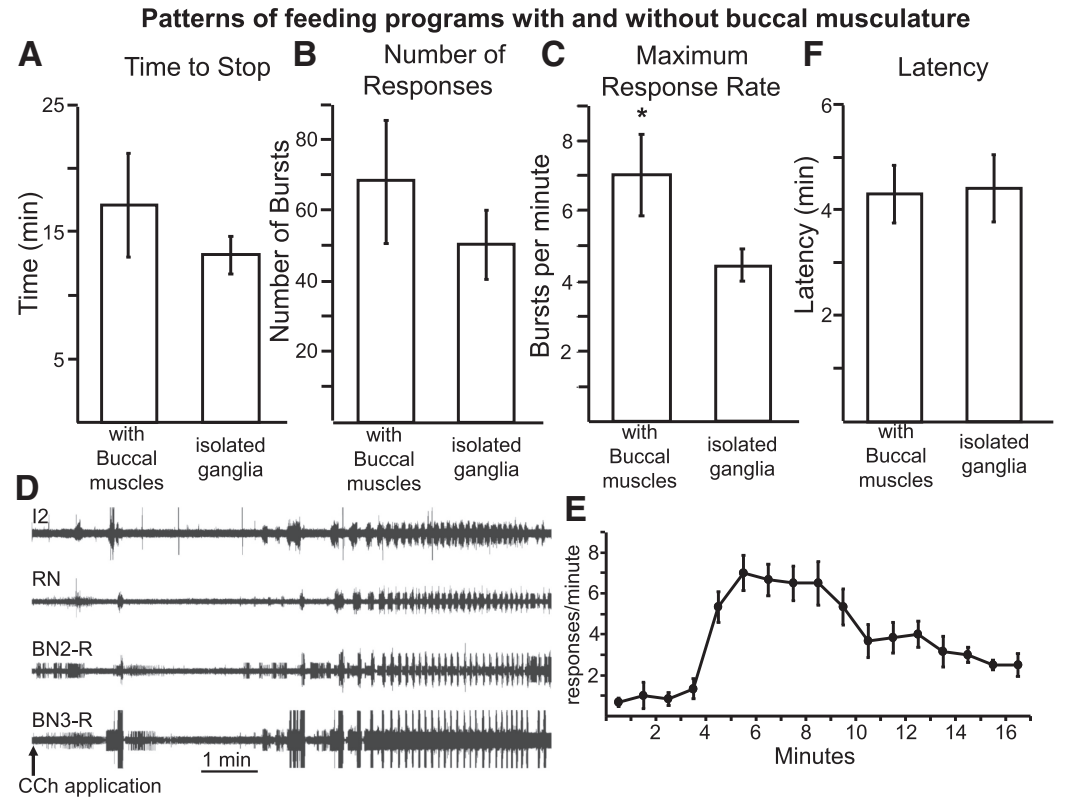

Figure 2. Parameters of motor responses induced by $\mathrm{CCh}$ with and without the buccal musculature. ( $A-C$ ) Summary data comparing response parameters in the presence and absence of the buccal musculature. Asterisks mark significant differences. Data on bursting in the absence of the buccal muscles are from the first of five repetitions with CCh applied to the cerebral ganglion that were reported in Susswein et al. (1996) $(N=10)$. Data on bursting in the presence of the buccal muscles is from the first of three repetitions with CCh applied to the cerebral ganglion reported in the present paper $(N=7)$. There were no significant differences between preparations with and without the buccal musculature for the total time that bursting was maintained $\left(P=0.17, t_{(14)}=1.44\right)$, or for the number of responses recorded during this period $\left(P=0.36, t_{(14)}=0.94\right)$. In contrast, the maximum response rate was higher when the musculature was attached $\left(P=0.01, t_{(13)}=3.00\right.$; all test are two-tailed $t$-tests), presumably as a result of proprioceptive feedback. (D-F) Latency and pattern of responses to CCh in a suspended buccal mass preparation. $(D)$ The CCh was applied 20-30 sec after the start of the recording in a preparation in which the buccal and cerebral ganglia remained attached to the buccal mass. Regular motor programs were initiated $\sim 5 \mathrm{~min}$ after the start of the recording. (I2) EMG recordings from the 12 muscle, which is active during protraction, (RN) recording from the radular nerve, which is a monitor of radular closing, (BN2-R) Recording from the right Buccal Nerve 2, which is active during retraction, (BN3-R) Recording from the right Buccal Nerve 3, in which the largest units are B4/B5, which are active at the start of retraction. (E) The number of responses per minute, from the application of $C C h$ onto the cerebral ganglion. Note that data are shown only from the first of three exposures to CCh (see below). The figure shows the mean and standard error of each minute for six of the seven preparations exposed to CCh alone. One preparation stopped responding within $6 \mathrm{~min}$ after the CCh was applied, and for this reason data from this preparation were are not included. Preparations differed in the length of time that they continued to respond. In the period shown in the figure, all six preparations continued to respond. Beyond this point, progressively fewer preparations continued to respond, and so these data are not shown. Note that the time at which responses began, and their rate of increase, differed somewhat for each preparation. The figure shows that after a delay, the rate of responses increased, and then slowly decreased. $(F)$ There was no significant difference in the latency from application of $\mathrm{CCh}$ to begin bursting between preparations with and without the buccal muscles $\left(P=0.91, t_{(15)}\right.$ $=0.11$; two-tailed $t$-test).

A striking feature of buccal motor programs elicited in intact animals (Susswein et al. 1978), and in isolated buccal-cerebral ganglia preparations stimulated with CCh (Susswein et al. 1996), is a delay between presentation of an adequate stimulus eliciting feeding, and the initiation of feeding activity. The delay reflects a lack of arousal in the absence of stimuli that elicit feeding. The feeding stimuli induce a feeding arousal before eliciting feeding behavior. The slow initiation of feeding was also seen in the suspended buccal mass preparation. Figure 2D illustrates the start of a trial in which CCh was applied to the cerebral ganglion in the suspended buccal mass preparation. After application of the CCh to the cerebral ganglion, motor programs are recorded after a latency of $\sim 4$ min. In Figure 2E, the frequency of the motor programs is shown for each minute after application of the CCh. After a delay, the mean frequency increased, and then gradually decreased, and eventually the preparations stopped responding. After the prepara- tion stopped responding (defined as no response for $60 \mathrm{sec}$ ), the CCh solution was washed from the cerebral ganglion chamber and was replaced with artificial seawater (ASW). The latencies from the exposure to the CCh to the start of bursting (Fig. 2F) were not significantly different in preparations in which the buccal muscles were present or absent.

\section{Modulation of protraction durations during $\mathrm{CCh}$ exposure in the presence of proprioceptive feedback}

Does the patterning of individual motor programs change during $\mathrm{CCh}$ exposure in addition to the changes in response rate? Although video recordings of the buccal mass were available, these were only intermittently useful in classifying the nature of feeding responses, since the radula was often not clearly visible. In addition, as noted above, it is difficult to relate extracellular nerve recordings in intact animals to the type of feeding behavior that intact animals perform, limiting the usefulness of nerve recording in classifying behaviors.

As a quantitative measure of some aspect of the nature of the motor programs, we measured the length of the protraction phase of activity. Protraction can vary from $<1 \mathrm{sec}$ to a maximum approaching $50 \mathrm{sec}$. Short protractions are indicative of weak radula protractions, which occur in swallowing, whereas long protractions are indicators of rejection activity (Hurwitz et al. 1996; Drushel et al. 1997; Ye et al. 2006a,b; Cullins et al. 2015). As the preparations became aroused, and the burst frequency increased, the length of the protractions decreased (Fig. 3A, left panel), indicating that long protractions are correlates of less than maximal arousal. We examined whether there were changes in the protraction length during the exposure to $\mathrm{CCh}$, as response frequency gradually decreased. The mean protraction lengths decreased during the first 10 responses (Fig. 3A, left panel), reaching a mean steady value of $3.4 \mathrm{sec}$. As the effect of the CCh wore off, and the response rate decreased, the protraction length increased. During the last 10 responses, protraction lengths were elevated, and were similar to those at the start of the response, when the preparation was just beginning to respond to $\mathrm{CCh}$, and response rates were relatively low (Fig 3A, right panel). Increased protraction length was not systematically tied to increased retraction length, since there were many examples of 20-40 sec protractions followed by relatively brief retractions.

We also compared the protraction lengths during the first half of the period during which bursting was sustained to the protraction lengths during the second half (Fig 3B). The distribution of protraction lengths was significantly shifted to longer protractions during the second half, reflecting a slowing of the frequency and a general decrease in efficacy of CCh in driving the motor programs. These data indicate that long protractions are more often present 
Changes in Protraction Length During CCh exposure

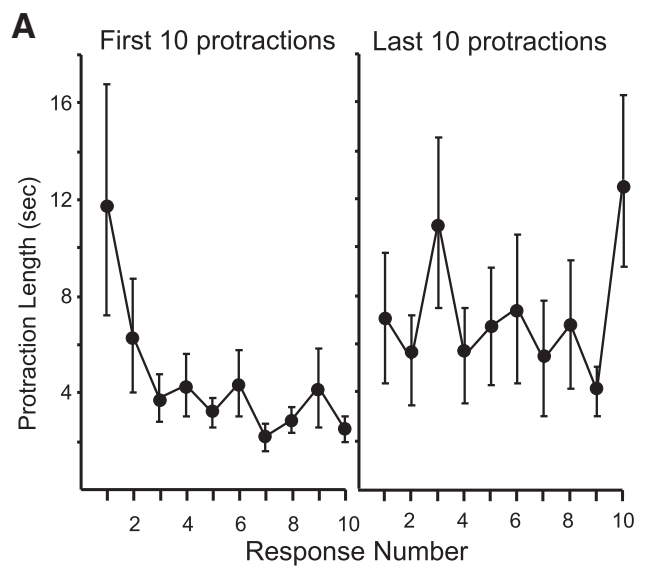

Figure 3. Changes in protraction length during the first exposure to $\mathrm{CCh}$. $(A)$ The mean protraction length during the first and last 10 feeding responses in six preparations exposed to CCh alone. Standard errors are shown. During the first few feeding responses, when response rate is low, protractions are relatively long. A one-way analysis of variance showed significant differences in protraction length among the first 10 protractions $\left(P=0.0007, F_{(9,53)}=3.91\right)$. To be certain that protraction length had reached baseline values, we elected to analyze protraction length from after the fifth response. During the last 10 responses, the protractions are similarly long. $(B)$ The time from the start of regular motor programs until the criterion for cessation was divided in halves, and the distribution of protraction lengths during each half was plotted. Bins are $1 \mathrm{sec}$ each. Since response rate is higher during the first half than during the second half, there are more protractions in the first half $(N=310)$ than in the second half $(N=154)$. To provide a common scale of frequencies, the frequency was expressed as a percentage of the total number of responses elicited by CCh. A Kolmogorov-Smirnov test showed that there was a significant difference in the distribution of the protraction lengths between the first and second halves $(D=0.2164$, $P<0.0001$ ), with a more prominent tail of long protractions found in the second half.

when the CCh is relatively ineffective in driving motor activity, and may be a general indicator of a preparation that is less responsive to stimuli driving feeding.

\section{Modulation of motor program patterning by edible or inedible foods}

To determine how the presence of edible or inedible foods might modulate the feeding motor activity, a number of parameters of the motor programs elicited by CCh were measured in preparations in which the cerebral ganglion was only stimulated by CCh $(N=7)$, as well as in preparations in which either edible [low-load] $(N=5)$ or inedible [high-load] $(N=9)$ foods were placed in the buccal mass after repeated responses had been initiated (Fig. 4). We were unable to measure possible influences of edible or inedible foods on the latency to begin responding, since food could be put into the mouth only after the preparations had begun to respond. However, we measured whether edible or inedible foods affected the total time that preparations remained responsive to the $\mathrm{CCh}$, the total number of responses from the start of a CCh application to the criterion for cessation of the buccal movements, the mean response rate, and the maximum response rate. There were no significant differences in time from the start of responses to cessation of responses between preparations treated with CCh alone and preparations that also were challenged with either edible or inedible food (Fig. 4A). In addition, there were no significant differences between the total number of responses elicited (Fig. 4B), or in the mean response rate (total number of responses/total response time) between the three treatments (Fig. 4C). However, there was a significant difference between the three groups in the peak response rate (Fig. 4D). A posthoc test showed no significant difference in peak response rate between preparations treated with $\mathrm{CCh}$ alone and those fed with inedible food. However, the maximal response rate between preparations fed with edible strips was significantly higher than was the maximal rate in response to $\mathrm{CCh}$ alone. The maximal response rate to edible strips was $\sim 10 / \mathrm{min}$, which is comparable to that in intact animals (Weiss et al. 1986).

It was also of interest to examine whether attempts to swallow edible or inedible foods affect the protraction length (Fig. 5A), since swallowing is characterized by weak protractions, which are relatively short, and rejection is characterized by strong protractions, which are relatively long (Hurwitz et al. 1996; Drushel et al. 1997; Ye et al. 2006b; Cullins et al. 2015). There was a significant difference in the distribution of protraction lengths between preparations treated with $\mathrm{CCh}$ alone and those also allowed to swallow edible food, with fewer long protractions in preparations that swallowed edible food. The shortened protractions in response to edible food is likely to be caused by such foods eliciting more swallowing responses.

A comparison of preparations treated with CCh alone and with $\mathrm{CCh}+$ inedible food showed no significant difference in distribution, using a Mann-Whitney $U$-test (which tests rankings), but showed a significant difference using a Kolmogorov-Smirnov test (which tests the overall distribution). These findings stress the general and surprising similarity of responses in preparations tested with CCh alone and those tested with $\mathrm{CCh}+$ inedible food, although they are not identical.

It was of interest to determine the protraction lengths when feeding activity is maximally driven by CCh treatment. Since the protraction length decreased while animals were becoming aroused, and then increased during the second half of the exposure to CCh alone, when the efficacy of the CCh was declining (see Fig. 3 ), we compared protraction length for the three treatments during the first half of the treatment, minus the first five feeding bouts, when protraction length is significantly decreasing (see Fig. $3 \mathrm{~A})$. There were significant differences in protraction lengths: Exposure to edible food caused a significant shortening of protraction, with respect to protraction during exposure to CCh alone, whereas exposure to inedible food caused a significant lengthening of protraction (Fig. 4E). The shortening of protraction with edible food is presumably a result of this food inducing swallows, in which protraction is relatively short (Hurwitz et al. 1996; Cullins et al. 2015). The lengthening of protraction with inedible food may arise because of increased attempts to reject the food, even when CCh is relatively effective in driving feeding activity; a characteristic of rejection is an increased protraction (Hurwitz et al. 1996; Ye et al. 2006b).

The similarity in the time to stop, number of responses and the response rate between the three types of preparations indicates that many features of the response in the three conditions are dictated by the properties of cerebral ganglion neurons responding to the CCh, irrespective of whether or not food in the buccal mass is loading the muscles. Nonetheless, protraction length and peak frequency are modulated by the presence of food in the buccal mass. Edible food caused an increase in peak frequency and a decrease in protraction length, whereas inedible food caused no change in response frequency, but increased protraction length. 


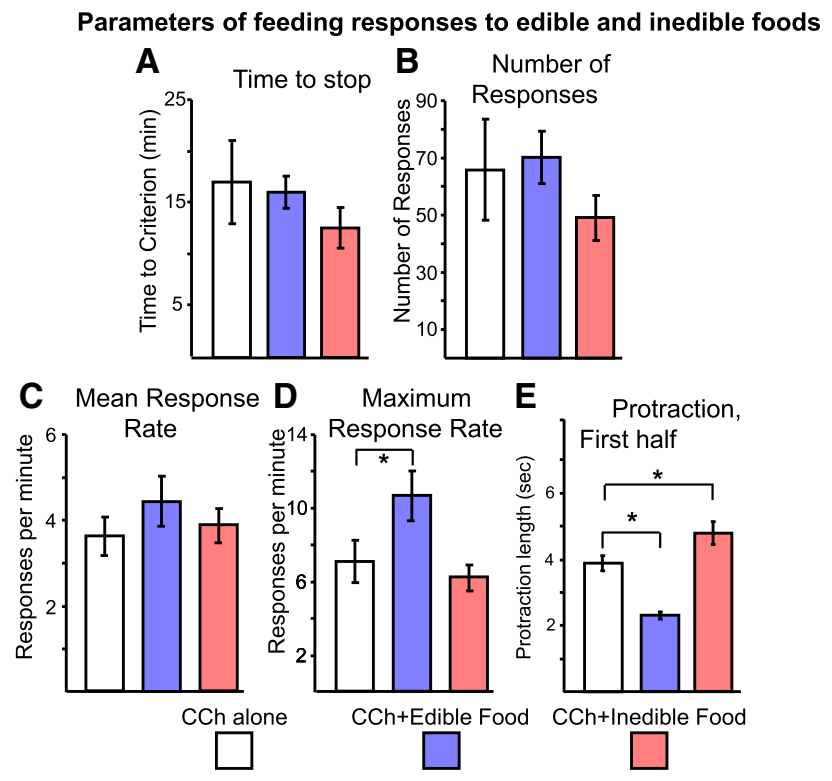

Figure 4. Parameters of feeding responses during the first exposure to CCh alone, and when either edible or inedible foods were also present. Asterisks mark significant differences. $(A)$ Time from the start of active bursting to the $60 \mathrm{sec}$ criterion for cessation of bursting. There was no significant difference between the three treatments $\left(P=0.48, F_{(2,18)}=0.77\right.$, one-way analysis of variance). (B) The total number of feeding responses elicited from the application of $\mathrm{CCh}$ until the criterion for cessation of response was reached. There was no significant difference between the three treatments $\left(P=0.44, F_{(2,18)}=0.87\right.$, one-way analysis of variance). (C) The mean response rate (defined as total number of responses/total response time (in minutes)). There was no significant difference between the three treatments $\left(P=0.52, F_{(2,18)}=0.67\right.$, one-way analysis of variance). $(D)$ The peak response rate. There was a significant difference between the three treatments $\left(P=0.02, F_{(2,18)}=4.78\right.$, one-way analysis of variance). A Tukey HSD post-hoc test showed no significant difference between preparations treated with $\mathrm{CCh}$ alone and those treated with $\mathrm{CCh}+$ inedible food $(P=0.80)$. The difference between preparations treated with $\mathrm{CCh}$ alone and those treated with $\mathrm{CCh}+$ edible food approached significance $(P=0.07)$. There was a significant increase in the maximum response rate in animals treated with $\mathrm{CCh}+$ edible food with respect to those treated with $\mathrm{CCh}+$ inedible food $(P=0.01)$. (E) Mean protraction lengths during the first half of the $\mathrm{CCh}$ exposure, with the first five feeding responses (when the preparation is not maximally aroused) removed (one of the seven preparation exposed to $\mathrm{CCh}$ alone had fewer than 20 responses, and so was not included in the analysis, since there were not enough responses to provide estimates of protraction length after the first five responses were subtracted). Edible food $(N=215$ protractions) showed significantly shortened protraction $(P<0.0002)$ compared to CCh alone $(N=277$ protractions), whereas inedible food $(N=202$ protractions) showed significantly lengthened protraction $(P=0.0452$, MannWhitney $U$-test, which was used because of the clear nonnormal distribution of protraction length-see Fig. 4).

\section{Short-term memory: effects of repeating treatments}

In intact Aplysia both successful and unsuccessful feeding produce learned changes in behavior (Susswein et al. 1986; Nargeot et al. 2007). Successfully consuming food produces an increased rate of responses, as well as a regularization of the responses (Nargeot et al. 2007). Failed attempts to consume food produce a faster decline in the time that animals respond to food, and to a reduction in the time that food remains in the mouth, perhaps because of an increase in rejection responses (Susswein et al. 1986; Schwarz et al. 1988), which are characterized by strong (and therefore long) protraction responses. To test the possibilities that either successful swallowing of food with a low load, or unsuccessful swallowing of food with a high load produces short-term memory in the reduced preparations, $\sim 60 \mathrm{~min}$ after the start of the trials reported above each of the three treatments was repeated, and the effects of a second application of $\mathrm{CCh}$, with or without edible or inedible foods, were measured. The repetition of the response to $\mathrm{CCh}$ alone served as a control for changes in the effect of CCh alone, independent of whether or not food was previously swallowed successfully.

There were no significant differences in the mean time to stop, or in the total number of responses elicited by CCh, between the preparations that were treated with $\mathrm{CCh}$ alone and preparations treated with either edible or inedible food (Fig. 6A,B). However, both the mean response rate and the maximal response rate were significantly elevated in preparations that swallowed edible food, with no significant differences between preparations treated with $\mathrm{CCh}$ alone and with $\mathrm{CCh}$ plus inedible food (Fig. $6 \mathrm{C}, \mathrm{D})$. Thus, edible food specifically elevated both the mean and maximal response rates.

Figure 6 compared parameters of feeding responses during the second exposure to $\mathrm{CCh}$ in preparations exposed to $\mathrm{CCh}$ alone and to $\mathrm{CCh}+$ edible or $\mathrm{CCh}+$ inedible food. However, it was also of interest to compare responses during the repetition of the CCh stimulation to the responses during the initial exposure to $\mathrm{CCh}$, one hour before. Such comparisons might show changes in response caused by the repetition of the exposure to $\mathrm{CCh}$, as well as possible additional effect of memory that may result from the previous attempts to eat edible or inedible foods. Data for each of the parameters measured, for each treatment, during the first and second treatments with $\mathrm{CCh}$, are shown separately in Supplemental Figure 1. To focus on the effects of repetition per se, treatments that are not statistically different from one another during the first exposure to CCh were combined, as were treatments that were not significantly different from one another during the second exposure to CCh.

For the time to stop responding, and for the total number of responses, there were significant decreases in response during the repetition (Fig. 7A,B). Since there are no differences for these parameters between preparations treated with $\mathrm{CCh}$ alone or with $\mathrm{CCh}+$ edible or inedible food, the decrease in responsivity could be explained by the exposure to CCh per se causing a reduction, with no evidence for an additional change in responses caused by the training with either edible or inedible food. For the mean and maximal response rates, there were also significant decreases during the second exposure in preparations treated with $\mathrm{CCh}$ alone and those treated with $\mathrm{CCh}+$ inedible food, indicating that the repetition of the CCh alone caused the decrease in responsivity, with no additional decrease caused by the exposure to the inedible food (Fig. 7C,D). However, for preparations that were treated with edible food, there were no significant decreases in either the mean or maximal response rates when comparing the data from the first and second exposures to $\mathrm{CCh}+$ edible food (Fig. 7C,D). These findings indicate that the ability to swallow food to some extent overcame the decline of responsiveness that results from the repetition of the exposure to CCh alone. The previous training with edible food may have produced short-term memory that was qualitatively similar to that produced in intact animals, in that the response rate was increased, although other parameters of feeding responses were similar to those in $\mathrm{CCh}$-treated controls. However, since we did not test the response to $\mathrm{CCh}+$ edible food after first exposing the preparation to $\mathrm{CCh}$ alone, we cannot rule out the possibility that the changes were caused by the previous exposure to CCh, independent of the presence of edible food. Surprisingly, the failed attempts to swallow food did not produce a decrease in response over that caused by the CCh alone.

We also tested whether there were significant differences in the length of the protraction phase of responses (Fig. 5B). There was a large, significant increase in the protraction length as a result of repeating the treatment with $\mathrm{CCh}$ alone, indicating a general 


\section{Swallowing foods and Repetition Affect Protraction Length}

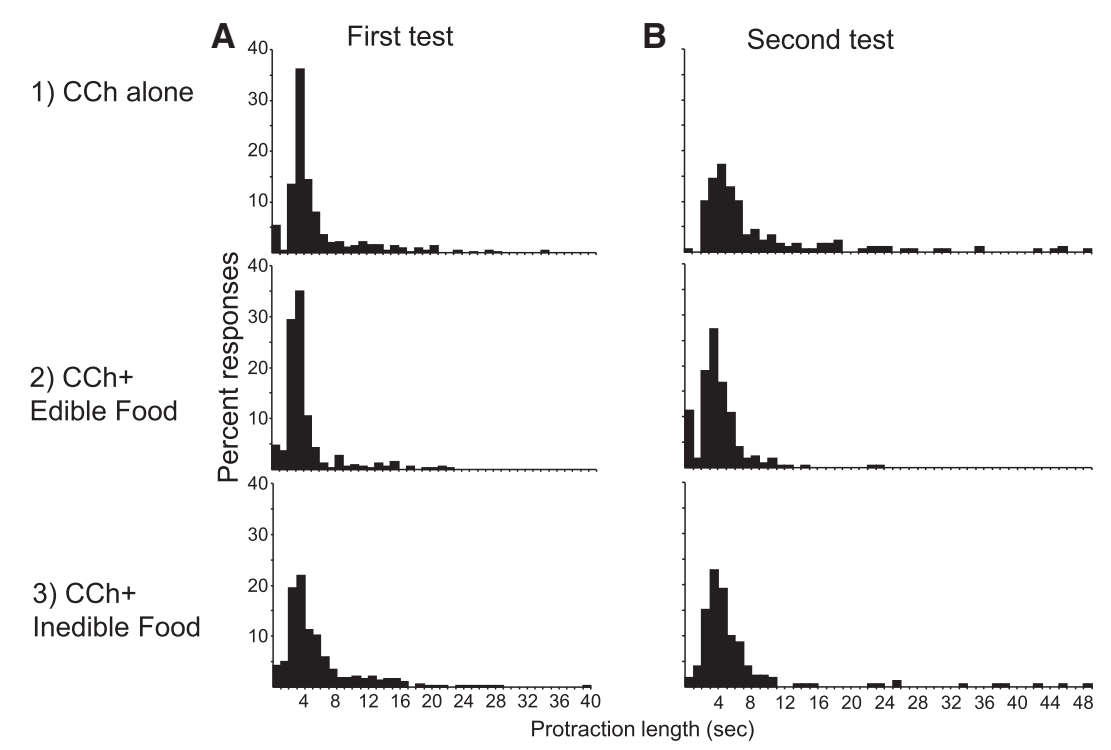

Figure 5. Distributions of protraction lengths in preparations treated with $\mathrm{CCh}$ alone, and in preparations treated with $\mathrm{CCh}$ and edible or inedible foods. As in Figure 3B, bins of the protraction lengths are 1 sec each. To provide a common scale of frequencies, the frequency was expressed as a percentage of the total number of responses from the application of $\mathrm{CCh}$ until the criterion for cessation of responses was reached. $(A)$ First treatment with $\mathrm{CCh}$. Kolmogorov-Smirnov tests showed that there were significant differences in the distribution of the protraction lengths between treatment with $C C h$ alone $(N=461)$ and with $C C h+$ edible food $(N=323)(P<0.0001, D=0.3189)$, and between $C C h$ alone and $C C h+$ in edible food $(N=379)(P=0.002, \mathrm{D}=0.1265)$. In addition, Mann-Whitney $U$-tests were performed to test whether the populations were ranked differently. There was a significant difference between $\mathrm{CCh}$ alone and $\mathrm{CCh}$ + edible food ( $P=0.002$, Mann-Whitney U-test with Bonferroni correction), but not between $C C h$ alone and $C C h+$ inedible food ( $P=0.50$, Mann-Whitney U-test). A comparison of protraction lengths in response to edible and inedible foods showed that protraction length in response to edible foods was significantly shorter than in response to inedible food $(P=0.018$, Mann-Whitney U-test with Bonferroni correction). The shortened protraction in response to edible food is likely to be because they elicited more swallowing responses, which are characterized by weak, short protractions. (B) The second treatment with CCh. Protraction lengths during the second exposure were compared to those during the first exposure, for the same treatments. Kolmogoroff- Smirnov tests were significant for CCh alone $(N=179)(P<0.001, D=0.2866)$ and for $C C h+$ edible food $(N=221)(P<0.001, D=0.2012)$, but not for $\mathrm{CCh}+$ inedible food $(N=171)(P=0.471, D=0.0770)$. Mann-Whitney U-tests with Bonferroni corrections (used because the data are not normally distributed) showed a significant increase in protraction length for preparations treated with $C C h$ alone $(P<0.0001)$, a significant decrease in protraction length for preparations treated with $\mathrm{CCh}+$ edible food $(P=0.009)$, and no significant change in protraction length in preparations treated with $\mathrm{CCh}+$ inedible food $(P=0.704)$.

decrease in effectiveness of CCh in driving motor activity. The increases in protraction length is consistent with the decrease in the number of responses, and with the decreased time that responses were maintained. The effect of repeating the $\mathrm{CCh}+$ edible food was opposite to that of repeating the $\mathrm{CCh}$ alone procedure: in place of a lengthening of the protractions, there was a small, but significant decrease in the protraction lengths after treatments with CCh + edible food, which is consistent with the improvement of some aspects of responsiveness as a result of the repetition of this treatment. Somewhat surprisingly, there was no significant change in protraction length between the first and second treatments with $\mathrm{CCh}+$ inedible foods $(P=0.704, \mathrm{Mann}-W h i t n e y \quad U$-test). Since long protractions are indicative of a general decrease in responsiveness, the lack of increased long protractions may reflect a possible improvement of some aspects of responsiveness over that induced by the repetition of CCh alone as a result of the repeated attempts to swallow the food, even if the attempts fail.

We also determined whether there were significant differences in protraction length when feeding activity is maximally driven by the CCh, during the first halves of the trials, after the preparation was fully aroused (Fig. 6E). A comparison of protraction length for the three treatments showed that there was a significant decrease in protraction length in response to edible food, but no change in protraction length in response to inedible food.

\section{A second test of short-term memory: effect of $\mathrm{CCh}$ alone after two training sessions}

In the above treatment, memory after the initial training was tested in response to the same stimulus combinations used during the training: preparations initially challenged with edible food were tested with edible food, and preparations that had been treated with inedible food were again given inedible food. The preparations tested twice with edible food showed improvement in some measures of responsiveness, with respect to controls treated with $\mathrm{CCh}$ alone, perhaps reflecting short-term memory. The preparations tested twice with inedible food showed no sign of decreased responsiveness using a number of measures of feeding.

Would there be indications of memory after treatment with either edible or inedible foods if the preparations were then treated a third time, but with CCh alone? We tested this possibility. Approximately 60 min after the start of the second exposure to CCh reported above, all preparations were exposed to $\mathrm{CCh}$ a third time. However, for this exposure, the preparations were not given either edible or inedible foods-all preparations were exposed only to the CCh (Fig. 8).

The results of this treatment were remarkably different from the results of the previous treatment. In this treatment, the preparations that had been previously exposed to inedible food showed strong evidence of memory similar with that seen in intact animals that are trained with the same inedible food. Thus, for three of four parameters measured (time to stop, number of responses, mean response rate), there were significant reductions in the responsiveness to the $\mathrm{CCh}$ alone in preparations that had previously been treated with inedible food, with no significant differences in any of the parameters between preparations that had been previously treated with $\mathrm{CCh}$ alone twice, or with edible food twice. The preparations that had been treated with inedible food responded significantly less to the CCh alone (see Fig. 8) than did either of the other two groups. These findings indicate that these preparations express short-term memory similar to that in intact animals, in spite of the lack of decreases in responses in previous training trials between treatment with $\mathrm{CCh}$ alone and treatment with inedible food. By contrast, the preparations treated with edible food did not express memory, as measured by these parameters, in spite of the possible memory shown in the previous trial.

It is possible that the decreased response to the CCh alone after two trials with $\mathrm{CCh}+$ inedible food is due to fatigue. To exclude this possibility, preparations that had previously been exposed to $\mathrm{CCh}+$ inedible food were presented with other stimuli that elicit motor activity (either dopamine applied to the buccal 


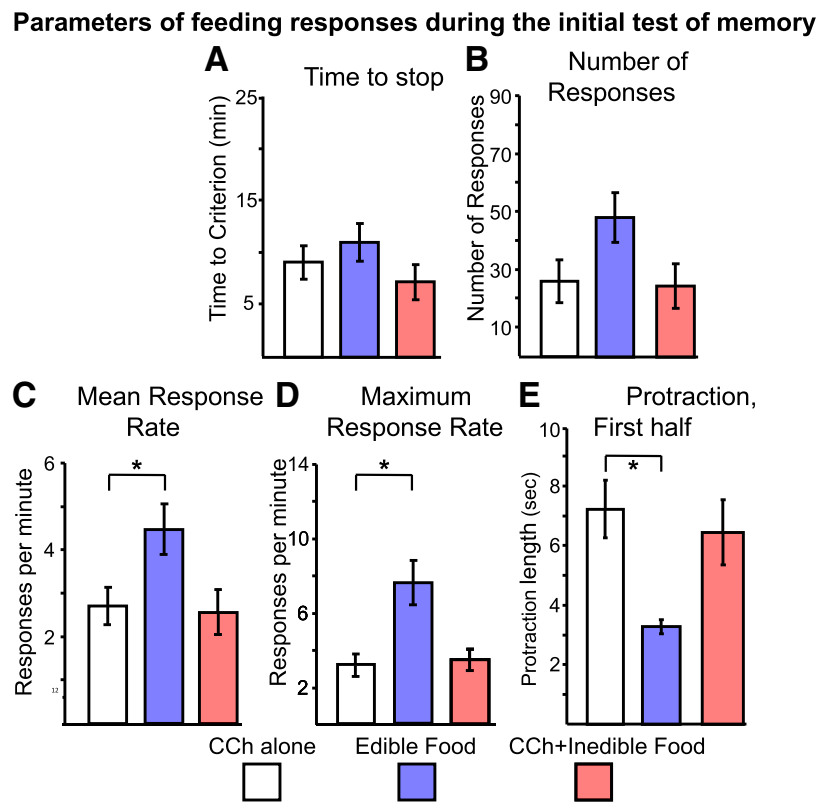

Figure 6. One hour after the start of the three treatments whose results are shown in Figures 4 and $5 \mathrm{~A}$, the treatments were repeated. Asterisks mark significant differences. $(A)$ There were no significant differences in the time to stop responding between the three treatments $(P=0.35$, $F_{(2,18)}=1.13$, one-way analysis of variance). $(B)$ There were no significant differences in the number of responses between the three treatments $\left(P=0.12, F_{(2,18)}=2.41\right.$, one-way analysis of variance). $(C)$ There was a significant difference in the mean response rate between the three treatments $\left(P=0.046, F_{(2,18)}=3.66\right.$, one-way analysis of variance). A Tukey HSD post-hoc test showed that there was no significant difference between preparations treated with $\mathrm{CCh}$ alone and those treated with $\mathrm{CCh}+$ inedible food $(P=0.90)$. By contrast, there was a significant difference between preparations treated with $\mathrm{CCh}+$ edible and $\mathrm{CCh}+$ inedible food $(P=0.039)$, and the difference between preparations treated with $\mathrm{CCh}$ alone and those treated with $\mathrm{CCh}+$ edible food approached significance $(P=0.088)$. (D) There was a significant difference in the maximum response rate between the three treatments $\left(P=0.008, F_{(2,18)}=6.38\right)$. A Tukey HSD post-hoc test showed that there was no significant difference between preparations treated with $\mathrm{CCh}$ alone and those treated with $\mathrm{CCh}+$ inedible food $(P=0.90)$. By contrast, there were significant differences between preparations treated with $\mathrm{CCh}+$ edible and $\mathrm{CCh}+$ inedible food $(P=0.014)$, and between preparations treated with $C C h$ alone and those treated with $\mathrm{CCh}+$ edible food $(P=0.012)$. $(E)$ Mean protraction lengths during the first half of the $C C h$ exposure, with the first five feeding responses (when the preparation is not maximally aroused) removed. Edible food ( $N=113$ protractions) significantly shortened protraction $(P<0.0001)$, with respect to $C C h$ alone $(N=79$ protractions), whereas inedible food ( $N=81$ protractions) had no significant effect on protraction $(P=0.023$; Mann-Whitney $U$-test).

ganglia, $N=2$, or stimulation of $\mathrm{BN} 2, N=1$ ). These stimuli elicited motor programs.

We also measured protraction length in preparations previously treated with CCh alone and in preparations exposed to $\mathrm{CCh}+$ edible food (Fig. 8E). Because seven of the nine preparations previously exposed to $\mathrm{CCh}+$ inedible responded with 10 or fewer feeding responses (the actual number of responses in the nine preparations were: $0,1,3,5,6,7,9,17,29$ ) it was not meaningful to measure protraction lengths in these preparations, because of the problem of heteroscedasticity. There were no significant differences in the overall protraction lengths between the preparations previously exposed twice to CCh alone or to $\mathrm{CCh}+$ edible food (Fig. $8 \mathrm{E})$. We also examined separately the protraction length during the first half of the exposures to $\mathrm{CCh}$, when protraction length is unaffected by the decline in responses to CCh (Fig. 8F). During the first half, the protractions in preparations that were previously treated with edible food were significantly shorter than were protractions in animals that were previously treated with CCh alone, indicating that there was some memory of the previous exposure to edible food.

\section{Discussion}

In higher animals and humans, different aspects of behavioral change that arise as a result of learning are localized to different

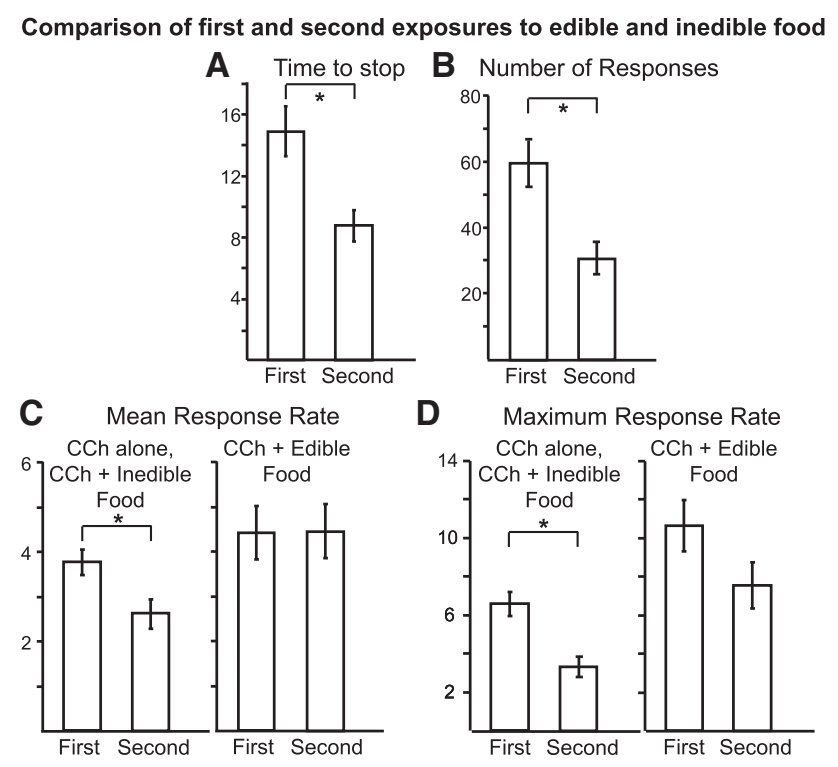

Figure 7. Comparison between parameters of feeding responses during the first and second test with CCh. Asterisks mark significant differences. $(A)$ Because there were no significant differences in the time to stop responding among the three groups tested in either the first or the second exposure to $\mathrm{CCh}$ (see Fig. 6A, B), data from the three treatments were combined for the first exposure to $\mathrm{CCh}$, and again for the second exposure to $\mathrm{CCh}$. The time to stop responding during the second exposure was significantly less than the time to stop during the first exposure to CCh $(P=0.002, t=3.64, d f=$ 20 , two-tailed paired $t$-test, comparing all preparations from the first to the second CCh exposure). (B) There was also no significant difference in number of responses between the three treatments during either of the exposures to $\mathrm{CCh}$, and therefore data were combined for each exposure to $\mathrm{CCh}$. The number of feeding responses during the second exposure was significantly less than the number of responses during the first exposure to $\mathrm{CCh}$ $(P=0.003, t=3.45, d f=20$, two-tailed paired $t$-test, comparing all preparations from the first to the second CCh exposure). (C) Because there were significant differences between the three treatments during the second exposure to $\mathrm{CCh}$, the mean response rate between the first and second exposures to $\mathrm{CCh}$ for the treatment that was significantly different from the other two ( $\mathrm{CCh}$ + edible food) was analyzed separately from the mean response rate for $\mathrm{CCh}$ alone and for inedible food, which were combined. There was a significant reduction in mean response rate for preparations treated with CCh alone and with $C C h+$ inedible food $(P=0.006, t=3.23$, $d f=15$, two-tailed paired $t$-test), with no significant difference for preparations treated with edible food $(P=0.95, t=0.07, \mathrm{df}=4$, two-tailed paired $t$-test). $(D)$ Because there were significant differences between the three treatments during both the first and second exposures to CCh for the maximal response rate, the values between the first and second exposures to $\mathrm{CCh}$ for the group that differed from the others $(\mathrm{CCh}+$ edible food) were analyzed separately, whereas data from the two groups that were not significantly different (CCh alone and CCh + inedible food) were combined. There was a significant reduction in mean response rate for preparations treated with CCh alone and with $C C h+$ inedible food $(P=0.0003, t=$ $4.75, d f=15$, two-tailed paired $t$-test), but not for preparations treated with CCh + edible food $(P=0.12, t=1.92, \mathrm{df}=4$, two-tailed paired $t$-test). Note that the data for the first and second exposures to CCh are plotted separately for each of the three procedures (i.e., no combining of data from different procedures) are presented in Supplemental Figure 1. 


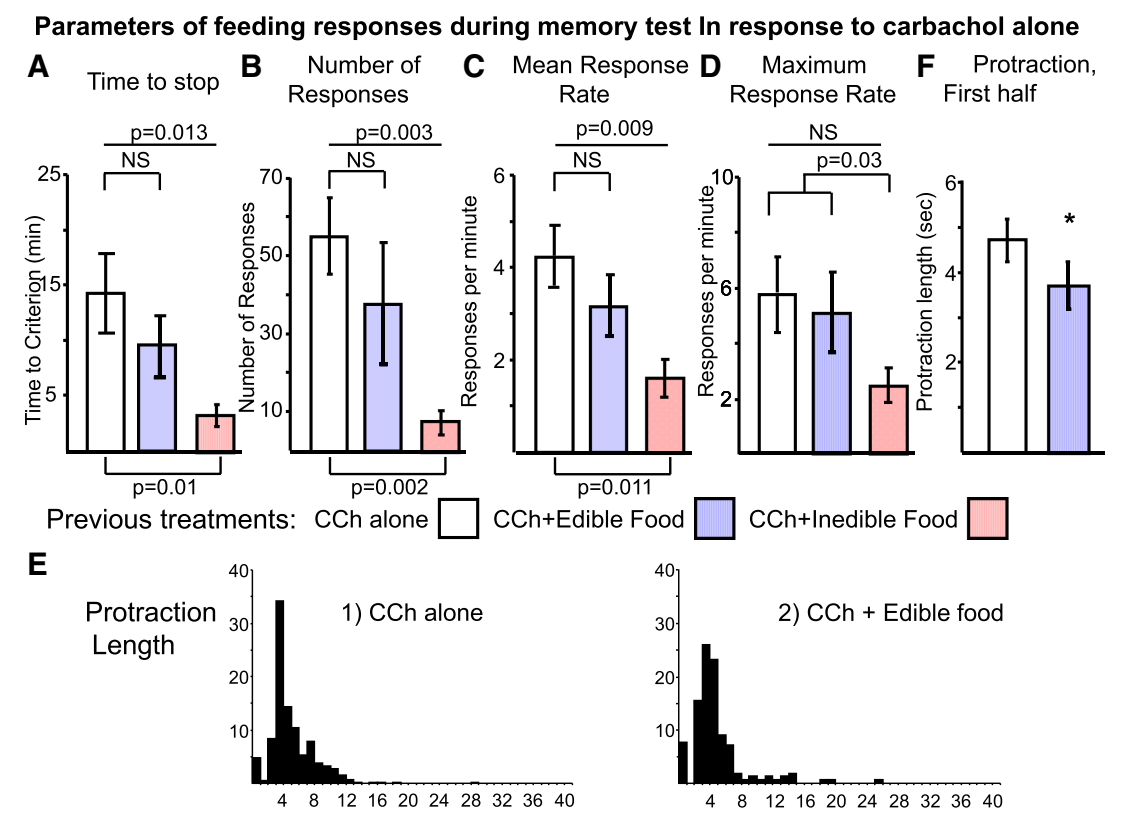

Figure 8. One hour after the start of the treatments whose results are shown in Figures 6 and 7 , a second test of memory examined the response to $C C h$ alone. $(A)$ There were significant differences in the time to stop responding based on which of the three treatments preceded the CCh alone $\left(P=0.013, F_{(2,18)}=5.55\right.$, one-way analysis of variance). The difference arose because of a decrease in response time of preparations that were previously treated with $\mathrm{CCh}$ + inedible food with respect to preparations previously treated with CCh alone ( $P=0.010$, Tukey HSD post-hoc test), with no significant difference between preparations previously treated with $C C h+$ edible food and $C C h$ alone $(P=0.46$, Tukey HSD post-hoc test). (B) There were significant differences in the number of responses to $\mathrm{CCh}$ alone based on which of the three treatments preceded the CCh alone $\left(P=0.003, F_{(2,18)}=8.31\right.$, one-way analysis of variance). The difference arose because of a decrease in response time of preparations that were previously treated with $\mathrm{CCh}+$ inedible food with respect to preparations previously treated with CCh alone $(P=0.002$, Tukey HSD post-hoc test), with no significant difference between preparations previously treated with $\mathrm{CCh}+$ edible food and $C C h$ alone $(P=0.44$, Tukey HSD post-hoc test). (C) There were significant differences in the mean response rate to $C C h$ alone, based on which of the three prior treatments was applied previously $(P=0.009$, $F_{(2,18)}=6.28$, one-way analysis of variance). The difference arose because of a decrease in response time of preparations that were previously treated with $\mathrm{CCh}+$ inedible food with respect to preparations previously treated with CCh alone $(P=0.011$, Tukey HSD post-hoc test), with no significant difference between preparations previously treated with $\mathrm{CCh}+$ edible food and CCh alone $(P=0.49$, Tukey HSD post-hoc test). $(D)$ There were no significant differences in the peak response rate to $C C h$ after the three preceding treatments $\left(P=0.08, F_{(2,18)}=2.85\right.$, one-way analysis of variance). However, when the data from preparations that were exposed previously to CCh alone and to $\mathrm{CCh}+$ edible food were combined, and were compared to data from preparations that had been previously exposed to $\mathrm{CCh}+$ inedible food, there was a significant difference $\left(P=0.026, t_{(19)}=2.41\right)$. In addition, there was a significant difference between preparations previously tested with $\mathrm{CCh}$ alone and those previously tested with $\mathrm{CCh}+$ inedible food $(P=0.03$, $\left.t_{(14)}=2.36\right)$. (E) Distribution of protraction lengths for preparations treated previously with (1) CCh alone $(N=392)$, and (2) CCh + edible food $(N=155)$. There were too few responses in seven of the nine preparations trained with inedible food to meaningfully compare preparations previously treated with $\mathrm{CCh}+$ inedible food to the other two groups. There were no significant differences in protraction length between the two groups shown (Kolmogorov-Smirnov test: $D=0.1124, P=0.112$; MannWhitney $U$-test: $U=27211, P=0.057)$. ( $F$ ) Comparison of protraction lengths during the first half of the exposure to $\mathrm{CCh}$ alone in preparations treated previously with $\mathrm{CCh}$ alone or with $\mathrm{CCh}+$ edible food. There was a significant decrease in protraction length in preparations previously treated with $\mathrm{CCh}+$ edible food ( $P=0.00022$, Mann-Whitney U-test) during the first half of exposure to $C C h$. Note that data on protraction lengths during the second half of all three treatments with CCh are shown in Supplemental Figure 2.

areas of the nervous system, which may operate via different mechanisms of neural plasticity. For example, in fear conditioning, a rodent placed in a new environment hears a tone, and is shocked. The animal learns to associate both the new environment and the tone with shock. The amygdala is involved in all forms of fear conditioning, but learning about the environment also requires changes in the hippocampus (Eichenbaum 2002; Sweatt 2009). Thus, a single learning event causes changes in different parts of the nervous system responsible for different aspects of behavioral change. The present findings show that aspects of memory formation after training with inedible food are localized to the cerebral ganglion. Earlier data indicated that aspects of memory are localized in the buccal ganglia (Levitan et al. 2008, 2012). Taken together, these results indicate that learning affecting Aplysia feeding is caused by changes in different ganglia causing different aspects of behavioral change. Thus, learning that food is inedible is similar to learning in higher animals, in that it is distributed to more than one site.

In this study, we investigated whether presence of the buccal musculature, or of feedback from swallowing, affect feeding motor programs elicited by a cholinomimetic. The cholinomimetic induces feeding, since $\mathrm{ACh}$ is the transmitter used by afferents responding to food in intact animals (Susswein et al. 1996). Because successful and unsuccessful swallowing produce memory when paired with attempts to feed, the investigation also provides insight into mechanisms underlying learning and memory. Figure 9 summarizes our findings.

\section{Effects of CCh on behavioral patterning}

Many features of the response to CCh are similar to those of intact animals in response to food, but some are different.

\section{Similarity of effects of CCh to in vivo behavior}

The latency from the exposure to CCh to the start of motor programs, and the gradual increase in response frequency (Fig. 2D-F), are remarkably similar to the phenomenon of food arousal in intact animals in response to lip stimulation (Kupfermann 1974a; Susswein et al. 1978), suggesting that food arousal in intact animals is triggered by $\mathrm{ACh}$ release in response to food. Hungry Aplysia in an environment without food are relatively unresponsive to food. Animals respond to food only after several minutes of exposure, after the food induces an arousal state. Some effects of food arousal are caused by activating neuron C-PR, which mediates aspects of appetitive feeding behaviors (Teyke et al. 1991; Nagahama et al. 1993). Additional aspects of food arousal are mediated by the serotonergic MCC neuron, which facilitates buccal ganglia motor neurons and muscles (Weiss et al. 1978). In intact animals, ACh released by taste afferents may act directly or indirectly on these neurons. The slow initiation of feeding indicative of initiation of arousal by CCh occurs in preparations in which the buccal muscles are not present (Susswein et al. 1996), and in preparations in which the ganglia remain attached to the muscles (Fig. 2D-F). The delayed response cannot be attributed to the time required for $\mathrm{CCh}$ to penetrate the connective tissue sheath covering the ganglion, since most of the delay was still seen when the sheath was removed (Susswein et al. 1996). The similarity of responses of intact animals to food and of reduced preparations to 


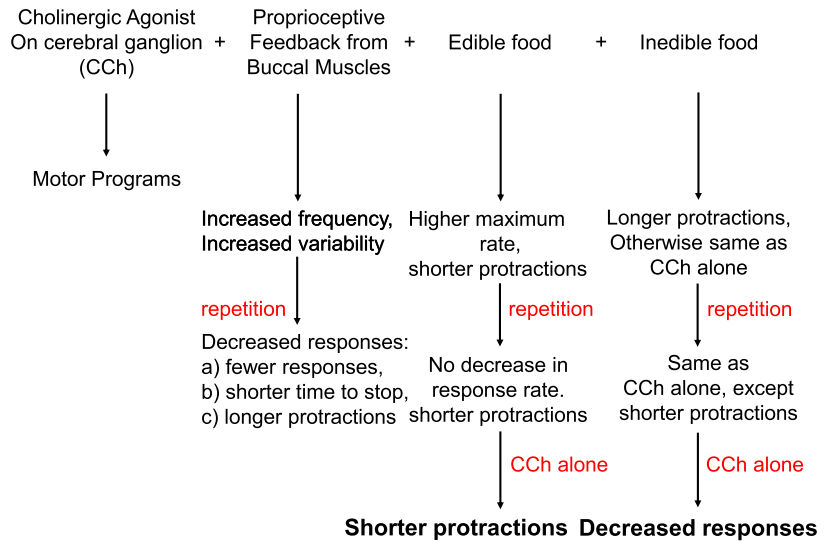

Figure 9. Summary of the findings. The cholinergic agonist CCh applied to the cerebral ganglion induces repetitive feeding motor programs. When the buccal muscles remain attached to the buccal ganglia, there is an increase in peak frequency, and an increase in the variability of the motor patterns. Repetition of this procedure leads to a decrease in responses, as measured by a shorter time that the preparation responds, fewer responses, and a lengthening of protractions. Challenging the preparation with edible food leads to an increase in mean and peak response rates, and a shortening of the protractions. Repetition of this procedure does not lead to the decrease in mean or peak response rates seen when the preparation is exposed to $\mathrm{CCh}$ alone, and leads to shorter protractions than during the initial training with edible food. Challenging the preparation with inedible foods causes responses that are similar to those to CCh alone during the training and during the repetition, except that the increased protraction length during the repetition does not occur, because protraction length is paradoxically decreased during the second half of the CCh exposure. When the preparations are again challenged with $\mathrm{CCh}$ alone, there are shorter protractions in preparations previously treated with $\mathrm{CCh}$ and edible food relative to preparations previously treated with CCh alone, with no other differences in other parameters of feeding. However, preparations previously treated with inedible food show reductions in many response parameters, showing memory similar to that in intact animals.

application of a cholinomimetic suggests that the delay in intact animals is not governed by a delay in the release of $\mathrm{ACh}$ in response to food, but rather by a delay in the response to ACh. The delay may be caused by a slow response of cholinoceptive neurons to the transmitter, or by delayed effects on downstream neurons receiving input from those responding to ACh.

The finding that the peak rate of motor programs was increased in the presence of the buccal musculature is consistent with findings on other repetitive movements, where a variety of sensorimotor interactions affect cyclical behavior (Pearson 2004; Rossignol et al. 2006). The increased response rate with the buccal muscles attached may occur because the buccal ganglia CPG governing repeated cycling is reset by feedback from the completion of the previous cycle of muscle activity, thereby phase advancing the next activity cycle. The stepping rate generated by a CPG in the spinal cord is sensitive to the hip angle, which may signal the completion of a step cycle, and changes in the hip angle can entrain rhythmic output (Kriellaars et al. 1994). In addition, a variety of spinal reflexes can modulate the CPG (Burke 1999). The peak response frequency is even higher with edible food, perhaps because opening of the esophageal sphincter allowing food to enter the gut may also signal that a cycle has ended, contributing to signals from the buccal muscles that the previous cycle has ended.

\section{Differences in effect of CCh from in vivo behavior}

Some features of motor programs elicited by CCh in the reduced preparation are markedly different from those in intact animals.
Thus, preparations stop responding to ACh in 10-20 min (Fig. 2B), whereas in intact animals food stimulating the lips elicits responses for over an hour (Schwarz et al. 1988). The maintained response in intact animals may reflect the release of other transmitters or of cotransmitters along with ACh (Weiss et al. 1993; Cropper et al. 2018), or of the effects of synaptic input from structures not present in the reduced preparation. The difference may also arise because CCh, rather than ACh was used in the reduced preparation. CCh is resistant to cholinesterase (Brown and Laiken 2011), which will lower the transmitter concentration after it is released. The maintained transmitter presence might lead to desensitization, and a shortening of its effective time. This possibility could be tested by using ACh in place of CCh.

A second possible difference is that a repeated exposure to $\mathrm{CCh}$ in the reduced preparation $1 \mathrm{~h}$ after initiation of the first response led to a reduction in parameters of responsiveness to food. Sustained lip stimulation in intact Aplysia does not produce long-term memory (Schwarz et al. 1988), but the effects of a rest similar to that in the present experiments have not been tested. The reduced response could arise because cholinergic receptors become desensitized by the maintained presence of the transmitter, and the period between transmitter applications is not sufficient to fully overcome the desensitization. Some reduction in response on repetition of CCh exposures was also seen in a previous report in which the cerebral ganglion was exposed to CCh for $20 \mathrm{~min} \mathrm{ev-}$ ery hour, over $5 \mathrm{~h}$ (Susswein et al. 1996).

\section{Effects of successful attempted swallows on behavioral patterning}

\section{Features of feeding responses not affected by attempts to swallow}

Features of individual motor programs and of sequences of responses seem to be separately regulated. Patterns of individual programs may be regulated by feedback from attempts to swallow (see below), but global features of responsiveness, such as the total time that the preparation is responsive, and the number of responses elicited, seem to be regulated by the exposure to the CCh per se, with limited effects of feedback from the attempts to swallow (Fig. 4A,B).

\section{Features of feeding responses affected by successful attempts to swallow}

Some features of the programs elicited by CCh were modulated by successful attempts to swallow, but not by unsuccessful swallowing attempts (Figs. 4-7), indicating that feedback from the success, rather than entry of food into the mouth, is the signal causing these modulations of motor activity. These effects are perhaps signaled by the opening of the esophageal sphincter. Another possibility is that performance of swallowing per se causes these effects, independent of success. However, the increased motor activity required to pull against inedible food inhibits the excitatory effects caused by swallowing, and the net effect of combined augmentation and inhibition of motor programs cancel one another when preparations attempt to swallow inedible food. This possibility is partially supported by the finding that some aspects of feeding are enhanced from the first to the second exposure to $\mathrm{CCh}$ in preparations tested with $\mathrm{CCh}+$ inedible food. Thus, there is a decrease in protraction length in the second half of the repetition of trials with $\mathrm{CCh}+$ inedible food (Supplemental Fig. 2B). A third possibility is that chemoreceptors in portions of the anterior gut that were still present enhanced responses. Successful swallowing in intact Aplysia produces a longer-lasting arousal dependent on chemical stimuli released by the food (Susswein et al. 1984b), which could enhance feeding responses elicited by CCh. 
Responses with edible foods are enhanced on repetition. The enhancement can be explained by a number of possibilities. The most interesting possibility is that enhancement arises from shortterm memory. Successful food consumption is a positive reinforcer in both classical and operant learning paradigms (Nargeot et al. 1997, 2007; Lechner et al. 2000; Brembs et al. 2002; Baxter and Byrne 2006; Lorenzetti et al. 2006), and the increased responsiveness on the repetition of $\mathrm{CCh}+$ edible food may arise from shortterm memory that results from the previous pairing. Another possibility is that the enhanced arousal caused by successful swallowing (Susswein et al. 1984b) produced a state change that was maintained when the stimulus was repeated. The maintained arousal is dependent on chemical stimuli released by the food (Susswein et al. 1984b). Another possibility is that swallowing responses elicited during the first exposure to $\mathrm{CCh}+$ edible food prime the feeding system, so that the system is biased to elicit swallowing when activated again. Repetition priming is present in the Aplysia feeding motor system (Friedman and Weiss 2010; Dacks et al. 2012; Cropper et al. 2017; Perkins et al. 2018). However, the priming should also be evident during the third exposure to $\mathrm{CCh}$, which was not paired with edible food. An additional possibility is that there is a ceiling effect on how much successful swallowing can facilitate CCh-elicited feeding responses. During the first exposure to $\mathrm{CCh}$, when the $\mathrm{CCh}$ is relatively effective, adding edible food produces a smaller enhancement of responses than during the second exposure to $\mathrm{CCh}$, when the $\mathrm{CCh}$ is less effective.

Much of the modulation of motor programs by successful swallowing is likely to be mediated by circuitry within the buccal ganglia, since neural correlates of short-term memory after successful swallowing are maintained even when the buccal ganglia are isolated (Nargeot et al. 2007). However, some modulation may also occur in the cerebral ganglion, since reduced protraction lengths were also seen when the preparation was stimulated by $\mathrm{CCh}$ alone applied after the training to the cerebral ganglion (Fig. 8F). The change in response to CCh could also arise by changes in the output of buccal to cerebral interneurons (Chiel et al. 1988), which could change the response of cerebral ganglion neurons to CCh.

One feature of feeding responses modulated by successful swallowing was the protraction length. Long protractions, which are indicative of strong protractions, were seen while the preparations were relatively unresponsive to the cholinomimetic, when they were becoming aroused, and when the responses to CCh were declining (Fig. 3A). Strong protraction is a characteristic of rejection, suggesting that these may be rejection programs. By contrast, successful swallowing was correlated with short protractions (Figs. 4E, 5A2,B2), which are correlates of swallowing responses (Hurwitz et al. 1996; Ye et al. 2006a,b; Cullins et al. 2015). Protraction length is partially set by the differential activity of different CBI neurons, which initiate motor programs with shorter or longer protractions (Jing et al. 2010), suggesting that some of the modulatory effects of eating edible foods, as well as some of the changes producing longer protractions after training with inedible food, may be produced by differentially selecting between different CBI neurons.

\section{Effects of failed attempts to swallow on behavioral patterning}

Training with inedible food produced no significant differences in most parameters of the feeding responses during either of the first two repetitions of $\mathrm{CCh}$ treatment, with respect to parameters produced by the CCh treatment alone (Figs. 4A-D, 6A-D, 7). The only parameter changed was the protraction length, which became longer during the first exposure to CCh (Figs. 4E, 5A). The mild changes in behavior observed are in marked contrast to the numerous changes in response in intact animals while they learn (Susswein et al. 1986).

In spite of the limited changes in behavior during the training, when preparations that were trained with $\mathrm{CCh}+$ inedible food were exposed to $\mathrm{CCh}$ alone, there were significant decreases in response that were similar to those seen in intact animals trained with inedible food (Fig. 8). These findings are consistent with previous data, which showed that long-term memory is blocked by treatments producing only relatively minor changes in behavior during the training (Katzoff et al. 2002), suggesting that separate processes may govern the behavioral changes while animals learn and the creation of memory from the learning experience (Briskin-Luchinsky et al. 2018b). However, we cannot exclude the possibility that one change found, the lengthened protractions during the initial trial with $\mathrm{CCh}+$ inedible food, contributed to the memory formation.

\section{Aspects of memory are localized to a postsynaptic decrease in $\mathrm{ACh}$ response in the cerebral ganglion}

The finding that after training with inedible food, exposure to $\mathrm{CCh}$ alone produces a remarkably reduced response suggests an explicit mechanism of memory: a postsynaptic decrease in response to $\mathrm{CCh}$ in cerebral ganglion neurons that are excited by taste cholinergic afferents. CCh applied to the cerebral ganglion may be the equivalent of a massive stimulation of all the cholinergic taste receptors. Pairing a response to ACh in cholinoceptive neurons initiating feeding with buccal ganglia information reporting aspects of unrewarded effort leads to a decreased sensitivity to ACh, and a decreased drive of buccal ganglia neurons that initiate feeding. The decrease in response to ACh released by sensory neurons would explain aspects of memory, such as a decrease in the time that animals continue to respond to food, without explaining the changes in behavior that occur while animals learn, which may be caused by changes in synaptic connectivity within the buccal ganglia.

A postsynaptic decrease in response to ACh released by sensory neurons also provides a mechanism for another aspect of memory, taste specificity. Both short-term and long-term memories are taste specific: after training with a particular food, animals show no memory when trained again with a food of another taste (Schwarz et al. 1988). We hypothesize that taste specificity arises by a localized postsynaptic decrease in response to ACh in only some of the receptors, leaving other receptors still responsive to ACh (Fig. 10). Foods of different tastes will activate different

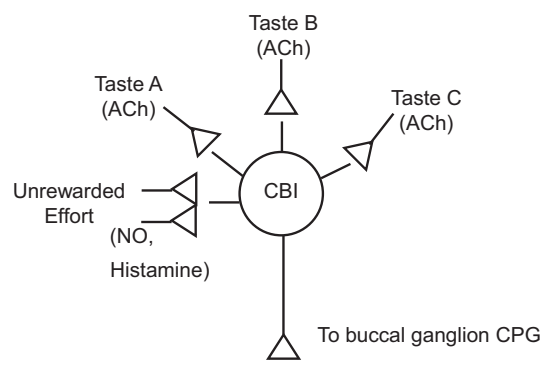

Figure 10. Hypothesis of mechanism of learning that food is inedible in the cerebral ganglion. Taste receptors respond to different tastes, but all release $A C h$ onto different neurites of command-like $C B I$ neurons. These excite the CPG within the buccal ganglia. Pairing activation of a specific taste with unrewarded effort, signaled by the release of Nitric Oxide (NO) and histamine (Susswein and Chiel 2012), causes a decrease in responsivity to ACh at the specific neurite (or combination of neurites) that were activated, while leaving intact the responses at neurites that were not paired with NO and histamine. 
populations of cholinergic afferents which synapse onto different local patches of the cerebral ganglion neurons initiating feeding. Natural foods will elicit activity in only a small sub-population of afferents, and only these afferents will display a decrease in response to ACh when paired with unrewarded effort. Sensory specificity arises by restricting a decreased response to ACh to a small number of postsynaptic sites, those that had been active in tandem with the stimuli that arise from unrewarded attempts to swallow. In response to other foods, postsynaptic cholinoceptive neurons will still respond to ACh. Taste specificity will arise because only some postsynaptic cholinoceptive sites were paired with the reinforcing signal (unrewarded effort), and only those sites will show a reduced response to $\mathrm{ACh}$, whereas other sites continue to respond to the ACh released by other taste receptors.

After the initial training with $\mathrm{CCh}+$ inedible food, a second exposure to $\mathrm{CCh}+$ inedible food provided a test of short-term memory. We found no trace of reduced responses indicative of memory similar to that in intact animals during this trial but did find memory expressed by a decreased responsiveness during the third test with CCh alone. Why was no reduction in responses seen during the second trial with CCh? One possibility is that training in the reduced preparation differs from that in intact animals, in that it requires two training sessions. This may be related to the differences in the training procedure in intact animals and in the reduced preparation. A second possibility is that memory would have been present during the second exposure to CCh, had we tested with CCh alone. However, the presence of inedible food in the second exposure produced a facilitation of feeding similar to that seen with edible food and obscured the decrease. This possibility is consistent with the reduction in protraction length seen during the second test (Supplemental Fig. 2B). A third possibility is that the $60 \mathrm{~min}$ time interval from the start of the training to the memory test was too long to pick up short-term memory, which in intact animals is seen at 30 min after training, but not at 60 min after training (Botzer et al. 1998). Repetition of training can produce intermediate-term memory (Botzer et al. 1998), and it is possible that the memory observed during the test with $\mathrm{CCh}$ alone is a form of intermediate-term memory, which would also be evident had we tested with $\mathrm{CCh}+$ inedible food, rather than with $\mathrm{CCh}$ alone. These possibilities could be examined by exposing the cerebral ganglion to $\mathrm{CCh}$ alone after a single training session with inedible food or changing the timing in which tests of memory are performed.

The inhibition of feeding activity after training with inedible food was seen $1 \mathrm{~h}$ after the start of the second training session, with no examination of possible preservation of memory for longer periods. However, training with inedible food in intact animals also produces longer-lasting memories that can be measured $24,48 \mathrm{~h}$, or even 3 wk after the training (Schwarz et al. 1991). Although different molecular processes are likely to underlie short- and longerterm memory, and even different types of long-term memory expressed at different times after training (Levitan et al. 2010), the behavioral expression of the different memory processes are remarkably similar, suggesting that they occur at the same neural sites, although via different molecular mechanisms. This suggests that a postsynaptic decrease in response to ACh may also underlie aspects of long-term memory. The expression of short-term and long-term memory at the same synapses is also a feature of other learning paradigms in Aplysia (Frost et al. 1985), as well as in mammalian systems (Squire and Kandel 2008).

Previous studies on molecular correlates of long-term memory formation showed increases after training in the buccal ganglia, but no changes in expression were found in the whole cerebral ganglion (Levitan et al. 2008; Michel et al. 2011; Briskin-Luchinsky et al. 2018a). However, changes in molecular correlates measured in the whole cerebral ganglia would not pick up changes localized to a small number of key neurons, such as the cholinoceptive command-like CBI neurons, leaving open the possibility that changes in the response to ACh may also underlie aspects of long-term memory. Previous reports (Briskin-Luchinsky et al. 2018a) also found that treatment with an NO donor produces changes in the cerebral ganglion, and the NO donor applied to the cerebral ganglion inhibits CCh-induced motor programs (Briskin-Luchinsky et al. 2018b), suggesting that the effects of NO on memory formation are localized to the cerebral ganglion.

The changes in gene expression in the buccal ganglia after training, coupled with the experiments above showing changes in the response to $\mathrm{CCh}$ in the cerebral ganglion, indicate that different aspects of memory after training with inedible food may be localized to different neural sites. The motor changes that occur while animals learn (decreased time in mouth stemming from fewer attempts to swallow and a greater likelihood to reject food), and that are also expressed during memory, may arise from changes in synaptic connectivity from buccal ganglia mechanoafferents to motor neurons. This is reflected by changes in gene expression in mechanoafferents (Levitan et al. 2012), and by changes in synaptic plasticity in monosynaptic connections from these mechanoafferents to identified motor neurons (Tam 2014). Many of the presumed behavioral correlates of the molecular and physiological consequences of training could not be expressed in the reduced preparation that we examined, since we forced the inedible foods to remain in the buccal cavity. The cessation of response to inedible food, and the taste specificity, are likely to arise via a decrease in response to $\mathrm{ACh}$ released from taste receptors onto a small group of command-like neurons in the cerebral ganglion. Thus, learning that food is inedible is similar to various learning paradigms in higher animals and in humans (Squire and Kandel 2008), in that learning leads to memory formation at multiple neural sites, with the different neural sites storing different aspects of behavioral change. Work on memory formation in invertebrate nervous systems has traditionally emphasized the molecular and physiological changes at a specific neural site, which gives rise to behavioral changes. The finding that Aplysia learning that food is inedible may arise from multiple changes at different neural sites, controlling different aspects of behavioral change, opens the possibility of using this preparation to explore the integration between different sites of plasticity to produce different aspects of an integrated change in behavior.

\section{Materials and Methods}

\section{Animals}

Aplysia californica weighing 250-350 g were purchased from Marinus and kept in aquaria filled with circulating artificial sea water (Instant Ocean; Aquarium Systems) at $\sim 16^{\circ} \mathrm{C}$. Animals were fed every other day with large strips of dried seaweed (laver). Before experiments, animals were presented with seaweed, and animals that displayed strong bites (large mouth opening with the radula protracting well beyond the mouth-see Susswein et al. 1976 for pictures) at 3- to 5-sec intervals were selected for use.

\section{Electrodes}

Hook electrodes were constructed from two wrapped, enamelcoated 0.001-in.-diameter stainless steel wires (California Fine Wire) that were coated in household silicone glue (GE). Before an experiment, the insulation was removed from the ends of the wires. One wire was attached to the target nerve or muscle with the use of Quick Gel Super Glue (Henkel) to insulate the wire from the saline and hold it in place; the other wire served as a reference. Signals were amplified using an AC-coupled differential amplifier (model 1700; A-M Systems). A 500-Hz low-pass filter 
and a $300-\mathrm{Hz}$ high-pass filter were used for nerve recordings. A $10-\mathrm{Hz}$ high-pass filter was used for muscle recordings.

\section{Experimental preparation}

The preparation used is described in detail elsewhere (McManus et al. 2012). Briefly, animals were anesthetized by injecting them with $25 \%$ of their weight with isotonic $\mathrm{MgCl}_{2}$. The buccal mass was removed, while still attached to the buccal and cerebral ganglia. The buccal mass and the attached buccal ganglia were suspended in ASW in a round $100 \mathrm{~mm}$ (diameter) $\times 50 \mathrm{~mm}$ (height) Pyrex dish. This dish had a front chamber in which the buccal mass was suspended, as well as a separate, elevated back chamber in which the cerebral ganglion was loosely pinned on a Sylgard substrate. The cerebral-buccal connective is placed in a notch in the Sylgard, thereby allowing neural communication between the two ganglia, while also allowing the cerebral ganglion to be bathed in a different solution from that bathing the buccal mass and the attached buccal ganglia.

Electrodes were attached to the Radula Nerve (RN), as well as onto buccal nerves 2 and 3 (BN2, BN3), and the electrodes recorded extracellular action potentials in these nerves. An additional electrode was attached to a strip of the I2 muscle. EMGs recorded in the I 2 muscle reflect radula protraction, which is produced by I2 contraction (Hurwitz et al. 1996). Large unit activity in the RN is a monitor of radula closing (Morton and Chiel 1993). BN3 activity is used to distinguish firing in identified neurons B4/B5, which are active at the start of retraction, primarily in rejection behavior (Warman and Chiel 1995; Jing and Weiss 2001; Ye et al. 2006b). Firing in BN2 is a monitor of retraction (Morton and Chiel 1993). In addition, a video camera recorded movement of the radula, from the side, and from the mouth.

\section{Stimulation with $\mathrm{CCh}$}

CCh was applied by replacing the Aplysia saline in the cerebral ganglion chamber with a solution of $10 \mathrm{mM} \mathrm{CCh}$ in Aplysia saline. The preparations responded with an increase in motor responses a number of minutes after the application. The CCh remained in the cerebral ganglion chamber as long as the preparation continued to respond to the $\mathrm{CCh}$. The criterion for cessation of responses was $60 \mathrm{sec}$ without a response, which is approximately the spontaneous response rate in the absence of CCh. Approximately 2-4 min after reaching the criterion, the CCh was washed out by removing and replacing the solution with fresh Aplysia saline four times. Parameters measured include: (1) the latency to begin responding to the CCh; (2) the time from the start of responses until the last response before the criterion was reached; (3) the total number of responses from the start of responses until the criterion; (4) the maximal response rate, which was calculated by counting the number of responses over $100 \mathrm{sec}$ after each response, and then expressing this number in responses per minute; (5) the length of the protraction phase, indicated by activity of the I 2 muscle.

\section{Loads}

Edible foods used to load the suspended buccal mass were strips of commercially bought laver (Nori) seaweed that were cut to be $0.25 \mathrm{~cm}$ wide and $8-10 \mathrm{~cm}$ long. Laver was used because it is easily cut into strips. After the preparations were responding at a regular rate in response to the CCh, a strip of food was placed within the mouth, eliciting swallows. The swallows successfully transferred the strip into the gut, and the strips exited through the cut end of the esophagus. After a full strip was swallowed, a second strip was placed within the mouth, thereby eliciting continued swallows.

Inedible food was used to load the buccal mass. The food used was identical to that used previously to train intact animals that food is inedible (Susswein et al. 1986; Botzer et al. 1998; Katzoff et al. 2002, 2006, 2010; Briskin-Luchinsky et al. 2018a,b), except that Gracilaria was used in place of Ulva. Laver was not used, since it is very soft, and pieces easily are swallowed Squares of plastic window netted were cut, and pieces of seaweed were placed within the center of the square. The square was then folded in half, folded again, and then a third time, with the seaweed located at the apex of the thrice-folded square. The folded square was held in a hemostat and was placed within the mouth when the response to the CCh became maximal. The inedible netted food was then released, allowing the preparation to attempt to swallow the netted food. The netted food occasionally was pushed outward as a result of rejection-like responses. The food was not allowed to exit the mouth: it was pushed back in before it exited.

\section{Statistics}

Parametric statistics were used for most measures of feeding. A number of on-line statistical calculators were used. Post-hoc tests after ANOVAs were performed at: http://astatsa.com/OneWay Anova_with_TukeyHSD/_get_data/. Protraction lengths were not normally distributed, and therefore nonparametric statistics were used. Mann-Whitney $U$-tests were performed at: https://www .socscistatistics.com/tests/mannwhitney/Default.aspx. KolmogorovSmirnov tests were performed at: http://www.physics.csbsju.edu/ stats/KS-test.n.plot_form.html.

\section{Acknowledgments}

The research was supported by Israel Science Foundation Grants 1379/12 and 2396/18, U.S.-Israel Binational Science Foundation Grant No. 2017624, and NSF-IOS-BSF Grant 1754869.

\section{References}

Antonov I, Kandel ER, Hawkins RD. 2010. Presynaptic and postsynaptic mechanisms of synaptic plasticity and metaplasticity during intermediate-term memory formation in Aplysia. J Neurosci 30: 57815791. doi:10.1523/JNEUROSCI.4947-09.2010

Baxter DA, Byrne JH. 2006. Feeding behavior of Aplysia: a model system for comparing cellular mechanisms of classical and operant conditioning. Learn Mem 13: 669-680. doi:10.1101/lm.339206

Botzer D, Markovich S, Susswein AJ. 1998. Multiple memory processes following training that a food is inedible in Aplysia. Learn Mem 5: 204219.

Brembs B, Lorenzetti FD, Reyes FD, Baxter DA, Byrne JH. 2002. Operant reward learning in Aplysia: neuronal correlates and mechanisms. Science 296: 1706-1709. doi:10.1126/science.1069434

Brezina V, Proekt A, Weiss KR. 2006. Cycle-to-cycle variability as an optimal behavioral strategy. Neurocomputing 69: 1120-1124. doi:10.1016/j .neucom.2005.12.057

Briskin-Luchinsky V, Levy R, Halfon M, Susswein AJ. 2018a. Molecular correlates of separate components of training that contribute to longterm memory formation after learning that food is inedible in Aplysia. Learn Mem 25: 90-99. doi:10.1101/lm.046326.117

Briskin-Luchinsky V, Tam S, Shabbat S, Hurwitz I, Susswein AJ. 2018b. NO is required for memory formation and expression of memory, and for minor behavioral changes during training with inedible food in Aplysia. Learn Mem 25: 206-213. doi:10.1101/lm.046474.117

Brown JH, Laiken N. 2011. Muscarinic receptor agonists and antagonists, chapter 9. In Goodman \& Gilman's the pharmacological basis of theraputics, 12th edn (ed. Brunton L, Chabner B, Knollmann B), pp. 219-238. McGraw-Hill, New York.

Burke RE. 1999. The use of state-dependent modulation of spinal reflexes as a tool to investigate the organization of spinal interneurons. Exp Brain Res 128: 263-277. doi: $10.1007 / \mathrm{s} 002210050847$

Chiel HJ, Beer RD. 1997. The brain has a body: adaptive behavior emerges from interactions of nervous system, body and environment. Trends Neurosci 20: 553-557. doi:10.1016/S0166-2236(97)01149-1

Chiel HJ, Susswein AJ. 1993. Learning that food is inedible in freely-behaving Aplysia californica. Behav Neurosci 107: 327-338. doi:10 .1037/0735-7044.107.2.327

Chiel HJ, Weiss KR, Kupfermann I. 1986. An identified histaminergic neuron modulates feeding motor circuitry in Aplysia. J Neurosci 6: 2427 2450. doi:10.1523/JNEUROSCI.06-08-02427.1986

Chiel HJ, Kupfermann I, Weiss KR. 1988. An identified histaminergic neuron can modulate the outputs of buccal-cerebral interneurons in Aplysia via presynaptic inhibition. J Neurosci 8: 49-63. doi:10.1523/ JNEUROSCI.08-01-00049.1988

Cohen TE, Kaplan SW, Kandel ER, Hawkins RD. 1997. A simplified preparation for relating cellular events to behavior: mechanisms contributing to habituation, dishabituation, and sensitization of the 
Aplysia gill-withdrawal reflex. J Neurosci 17: 2886-2899. doi:10.1523/ JNEUROSCI.17-08-02886.1997

Cropper EC, Evans CG, Hurwitz I, Jing J, Proekt A, Romero A, Rosen SC. 2004. Feeding neural networks in the mollusc Aplysia. Neurosignals 13: 70-86. doi:10.1159/000076159

Cropper EC, Jing J, Perkins MH, Weiss KR. 2017. Use of the Aplysia feeding network to study repetition priming of an episodic behavior. $J$ Neurophysiol 118: 1861-1870. doi:10.1152/jn.00373.2017

Cropper EC, Jing J, Vilim FS, Barry MA, Weiss KR. 2018. Multifaceted expression of peptidergic modulation in the feeding system of Aplysia. ACS Chem Neurosci 9: 1917-1927. doi:10.1021/acschemneuro.7b00447

Cullins MJ. 2014. Parsing variability: variability in Aplysia feeding motor programs and behavioral performance due to behavioral differences, individuality, and sensory feedback. PhD thesis, Case Western Reserve University, Cleveland, OH. https://etd.ohiolink.edu/!etd.send_file? accession=case $1400677648 \&$ disposition=inline.

Cullins MJ, Shaw KM, Gill JP, Chiel HJ. 2015. Motor neuronal activity varies least among individuals when it matters most for behavior. $J$ Neurophysiol 113: 981-1000. doi:10.1152/jn.00729.2014

Dacks AM, Siniscalchi MJ, Weiss KR. 2012. Removal of default state-associated inhibition during repetition priming improves response articulation. J Neurosci 32: 17740-17752. doi:10.1523/JNEUROSCI $.4137-12.2012$

Dembrow NC, Jing J, Proekt A, Romero A, Vilim FS, Cropper EC, Weiss KR. 2003. A newly identified buccal interneuron initiates and modulates feeding motor programs in Aplysia. J Neurophysiol 90: 2190-2204. doi:10 $.1152 /$ jn.00173.2003

Diehl F, White RS, Stein W, Nusbaum MP. 2013. Motor circuit-specific burst patterns drive different muscle and behavior patterns. J Neurosci 33: 12013-1229. doi:10.1523/JNEUROSCI.1060-13.2013

Drushel RF, Neustadter DM, Shallenberger LL, Crago PE, Chiel HJ. 1997. The kinematics of swallowing in the buccal mass of Aplysia californica.J Exp Biol 200: $735-752$.

Eichenbaum H. 2002. The cognitive neuroscience of memory: an introduction. Oxford University, New York.

Elliott CJ, Susswein AJ. 2002. Comparative neuroethology of feeding control in molluscs. J Exp Biol 205: 877-896.

Friedman AK, Weiss KR. 2010. Repetition priming of motoneuronal activity in a small motor network: intercellular and intracellular signaling. $J$ Neurosci 30: 8906-8919. doi:10.1523/JNEUROSCI.1287-10.2010

Frost WN, Castellucci VF, Hawkins RD, Kandel ER. 1985. Monosynaptic connections made by the sensory neurons of the gill- and siphon-withdrawal reflex in Aplysia participate in the storage of long-term memory for sensitization. Proc Natl Acad Sci 82: 8266-8269. doi:10.1073/pnas.82.23.8266

Frost L, Kaplan SW, Cohen TE, Henzi V, Kandel ER, Hawkins RD. 1997. A simplified preparation for relating cellular events to behavior: contribution of LE and unidentified siphon sensory neurons to mediation and habituation of the Aplysia gill- and siphon-withdrawal reflex. J Neurosci 17: 2900-2913. doi:10.1523/JNEUROSCI.17-08-02900 .1997

Hamood AW, Marder E. 2015. Consequences of acute and long-term removal of neuromodulatory input on the episodic gastric rhythm of the crab Cancer borealis. J Neurophysiol 114: 1677-1692. doi:10.1152/jn .00536 .2015

Hurwitz I, Susswein AJ. 1996. B64, a newly identified central pattern generator element producing a phase switch from protraction to retraction in buccal motor programs of Aplysia californica. J Neurophysiol 75: $1327-1344$. doi:10.1152/jn.1996.75.4.1327

Hurwitz I, Goldstein RS, Susswein AJ. 1994. Compartmentalization of pattern-initiation and motor functions in the B31 and B32 neurons of the buccal ganglia of Aplysia californica. J Neurophysiol 71: 1514-1527. doi:10.1152/jn.1994.71.4.1514

Hurwitz I, Neustadter D, Morton D, Chiel HJ, Susswein AJ. 1996. Activity patterns of the B31/B32 pattern initiators innervating the I2 muscle of the buccal mass during normal feeding movements in Aplysia californica. J Neurophysiol 75: 1309-1326. doi:10.1152/jn.1996.75.4.1309

Hurwitz I, Kupfermann I, Susswein AJ. 1997. Different roles of neurons B63 and B34 that are active during the protraction phase of buccal motor programs in Aplysia californica. J Neurophysiol 78: 1305-1319. doi:10 $.1152 /$ jn.1997.78.3.1305

Hurwitz I, Perrins R, Xin Y, Weiss KR, Kupfermann I. 1999. C-PR neuron of Aplysia has differential effects on "Feeding" cerebral interneurons, including myomodulin-positive CBI-12. J Neurophysiol 81: 521-534. doi:10.1152/jn.1999.81.2.521

Hurwitz I, Kupfermann I, Weiss KR. 2003. Fast synaptic connections from CBIs to pattern-generating neurons in Aplysia: initiation and modification of motor programs. J Neurophysiol 89: 2120-2136. doi:10 $.1152 /$ jn.00497.2002

Hurwitz I, Ophir A, Korngreen A, Koester J, Susswein AJ. 2008. Currents contributing to decision-making in neurons B31/B32 of Aplysia. J Neurophysiol 99: 814-830. doi:10.1152/jn.00972.2007
Jing J, Weiss KR. 2001. Neural mechanisms of motor program switching in Aplysia. J Neurosci 21: 7349-7362. doi:10.1523/JNEUROSCI .21-18-07349.2001

Jing J, Weiss KR. 2005. Generation of variants of a motor act in a modular and hierarchical motor network. Curr Biol 15: 1712-1721. doi:10.1016/j .cub.2005.08.051

Jing J, Sweedler JV, Cropper EC, Alexeeva V, Park JH, Romanova EV, Xie F, Dembrow NC, Ludwar BC, Weiss KR, et al. 2010. Feedforward compensation mediated by the central and peripheral actions of a single neuropeptide discovered using representational difference analysis. J Neurosci 30: 16545-16558. doi:10.1523/JNEUROSCI.4264-10.2010

Katzoff A, Ben-Gedalya T, Susswein AJ. 2002. Nitric oxide is necessary for multiple memory processes after learning that a food is inedible in Aplysia. J Neurosci 22: 9581-9594. doi:10.1523/JNEUROSCI 22-21-09581.2002

Katzoff A, Ben-Gedalya T, Hurwitz I, Miller N, Susswein YZ, Susswein AJ. 2006. Nitric oxide signals that Aplysia have attempted to eat, a necessary component of memory formation after learning that food is inedible. $J$ Neurophysiol 96: 1247-1257. doi:10.1152/jn.00056.2006

Katzoff A, Miller N, Susswein AJ. 2010. Nitric oxide and histamine signal attempts to swallow: a component of learning that food is inedible Aplysia. LearnMem 17: 50-62.

Kriellaars DJ, Brownstone RM, Noga BR, Jordan LM. 1994. Mechanical entrainment of fictive locomotion in the decerebrate cat. J Neurophysiol 71: 2074-2086.

Kupfermann I. 1974a. Feeding behavior in Aplysia: a simple system for the study of motivation. Behav Biol 10: 1-26. doi:10.1016/S0091-6773(74) 91644-7

Kupfermann I. 1974b. Dissociation of the appetitive and consummatory phases of feeding behavior in Aplysia: a lesion study. Behav Biol 10: 8997. doi:10.1016/S0091-6773(74)91694-0

Kupfermann I, Carew TJ. 1974. Behavior patterns of Aplysia californica in its natural environment. Behav Biol 12: 317-37. doi:10.1016/S0091-6773 (74)91503-X

Lechner HA, Baxter DA, Byrne JH. 2000. Classical conditioning of feeding in Aplysia: I. Behavioral analysis. J Neurosci 20: 3369-3376. doi:10.1523/ JNEUROSCI.20-09-03369.2000

Levitan D, Lyons LC, Perelman A, Green CL, Motro B, Eskin A, Susswein AJ. 2008. Training with inedible food in Aplysia causes expression of C/EBP in the buccal but not cerebral ganglion. Learn Mem 15: 412-416. doi:10 $.1101 / \operatorname{lm} .970408$

Levitan D, Twitto R, Levy R, Lyons L, Susswein AJ. 2010. A brief retraining regulates the persistence and lability of a long-term memory. Learn Mem 17: 402-406. doi:10.1101/lm.1820010

Levitan D, Saada-Madar R, Teplinsky A, Susswein AJ. 2012. Localization of molecular correlates of memory consolidation to buccal ganglia mechanoafferent neurons after learning that food is inedible in Aplysia. Learn Mem 19: 503-512. doi:10.1101/lm.026393.112

Lorenzetti FD, Mozzachiodi R, Baxter DA, Byrne JH. 2006. Classical and operant conditioning differentially modify the intrinsic properties of an identified neuron. Nat Neurosci 9: 17-19. doi:10.1038/nn1593

Marder E, Bucher D. 2001. Central pattern generators and the control of rhythmic movements. Curr Biol 11: R986-R996. doi:10.1016/ S0960-9822(01)00581-4

McManus JM, Lu H, Chiel HJ. 2012. An in vitro preparation for eliciting and recording feeding motor programs with physiological movements in Aplysia californica. J Vis Exp e4320. doi:10.3791/4320. doi:10.3791/4320

McManus JM, Lu H, Cullins MJ, Chiel HJ. 2014. Differential activation of an identified motor neuron and neuromodulation provide Aplysia's retractor muscle an additional function. J Neurophysiol 112: 778-791. doi:10.1152/jn.00148.2014

Michel M, Green CL, Eskin A, Lyons LC. 2011. PKG-mediated MAPK signaling is necessary for long-term operant memory in Aplysia. Learn Mem 18: 108-117. doi:10.1101/lm.2063611

Morton DW, Chiel HJ. 1993. In vivo buccal nerve activity that distinguishes ingestion from rejection can be used to predict behavioral transitions in Aplysia. J Comp Physiol A 172: 17-32. doi:10.1007/BF00214712

Nagahama T, Weiss KR, Kupfermann I. 1993. Effects of cerebral neuron C-PR on body postural muscles associated with a food-induced arousal state in Aplysia. J Neurophysiol 70: 1231-1243. doi:10.1152/jn.1993.70.3.1231

Nargeot R, Baxter DA, Byrne JH. 1997. Contingent-dependent enhancement of rhythmic motor patterns: an in vitro analog of operant conditioning. J Neurosci 17: 8093-8105. doi:10.1523/JNEUROSCI 17-21-08093.1997

Nargeot R, Baxter DA, Byrne JH. 1999. In vitro analog of operant conditioning in Aplysia. I. Contingent reinforcement modifies the functional dynamics of an identified neuron. J Neurosci 19: 2247-2260. doi:10.1523/JNEUROSCI.19-06-02247.1999

Nargeot R, Petrissans C, Simmers J. 2007. Behavioral and in vitro correlates of compulsive-like food seeking induced by operant conditioning in Aplysia. J Neurosci 27: 8059-8070. doi:10.1523/JNEUROSCI.1950-07 .2007 
Neustadter DM, Drushel RF, Crago PE, Adams BW, Chiel HJ. 2002. A kinematic model of swallowing in Aplysia californica based on radula/ odontophore kinematics and in vivo magnetic resonance images. J Exp Biol 205: 3177-3206.

Neustadter DM, Herman RL, Drushel RF, Chestek DW, Chiel HJ. 2007. The kinematics of multifunctionality: comparisons of biting and swallowing in Aplysia californica. J Exp Biol 210: 238-260. doi:10.1242/jeb.02654

Neveu CL, Costa RM, Homma R, Nagayama S, Baxter DA, Byrne JH. 2017. Unique configurations of compression and truncation of neuronal activity underlie l-DOPA-induced selection of motor patterns in Aplysia. eNeuro 4: ENEURO.0206-17.2017. doi:10.1523/ENEURO.0206-17.2017.

Pearson KG. 2004. Generating the walking gait: role of sensory feedback. Prog Brain Res 143: 123-129. doi:10.1016/S0079-6123(03)43012-4

Perkins MH, Cropper EC, Weiss KR. 2018. Cellular effects of repetition priming in the Aplysia feeding network are suppressed during a task-switch but persist and facilitate a return to the primed state. $J$ Neurosci 38: 6475-6490. doi:10.1523/JNEUROSCI.0547-18.2018

Rosen SC, Teyke T, Miller MW, Weiss KR, Kupfermann I. 1991. Identification and characterization of cerebral-to-buccal interneurons implicated in the control of motor programs associated with feeding in Aplysia. J Neurosci 11: 3630-3655. doi:10.1523/JNEUROSCI .11-11-03630.1991

Rossignol S, Dubuc R, Gossard JP. 2006. Dynamic sensorimotor interactions in locomotion. Physiol Rev 86: 89-154. doi:10.1152/physrev.00028 .2005

Saada R, Miller N, Hurwitz I, Susswein AJ. 2009. Autaptic excitation elicits persistent activity and a plateau potential in a neuron of known behavioral function. Curr Biol 19: 479-484. doi:10.1016/j.cub.2009.01 .060

Sasaki K, Due MR, Jing J, Weiss KR. 2007. Feeding CPG in Aplysia directly controls two distinct outputs of a compartmentalized interneuron that functions as a CPG element. J Neurophysiol 98: 3796-3801. doi:10.1152/ jn.00965.2007

Schwarz M, Markovich S, Susswein AJ. 1988. Parametric features of inhibition of feeding in Aplysia by associative learning, satiation and sustained lip stimulation. Behav Neurosci 102: 124-133. doi:10.1037/ 0735-7044.102.1.124

Schwarz M, Feldman E, Susswein AJ. 1991. Variables affecting long-term memory of learning that a food is inedible in Aplysia. Behav Neurosci 105: 193-201. doi:10.1037/0735-7044.105.1.193

Squire LR, Kandel ER. 2008. Memory: from mind to molecules, 2nd edn. Roberts \& Company, Greenwood Village, Colorado.

Susswein AJ, Byrne JH. 1988. Identification and characterization of neurons initiating patterned neural activity in the buccal ganglia of Aplysia. J Neurosci 8: 2049-2061. doi:10.1523/JNEUROSCI.08-06-02049.1988

Susswein AJ, Chiel HJ. 2012. Nitric oxide as a regulator of behavior: new ideas from Aplysia feeding. Prog Neurobiol 97: 304-317. doi:10.1016/j .pneurobio.2012.03.004

Susswein AJ, Kupfermann I, Weiss KR. 1976. The stimulus control of biting in Aplysia. J Comp Physiol 108: 75-96. doi:10.1007/BF00625442

Susswein AJ, Weiss KR, Kupfermann I. 1978. The effects of food arousal on the latency of biting in Aplysia. J Comp Physiol 123: 31-41. doi:10.1007/ BF00657341

Susswein AJ, Gev S, Achituv Y, Markovich S. 1984a. Behavioral patterns of Aplysia fasciata along the Mediterranean coast of Israel. Behav Neural Biol 41: 7-22. doi:10.1016/S0163-1047(84)90667-8
Susswein AJ, Weiss KR, Kupfermann I. 1984b. Internal stimuli enhance feeding behavior in the mollusc Aplysia. Behav Neural Biol 41: 90-95. doi:10.1016/S0163-1047(84)90784-2

Susswein AJ, Schwarz M, Feldman E. 1986. Learned changes of feeding behavior in Aplysia in response to edible and inedible foods. J Neurosci 6: 1513-1527. doi:10.1523/JNEUROSCI.06-05-01513.1986

Susswein AJ, Rosen SC, Gapon S, Kupfermann I. 1996. Characterization of buccal motor programs elicited by a cholinergic agonist applied to the cerebral ganglion of Aplysia californica. J Comp Physiol A 179: 509-524. doi:10.1007/BF00192317

Sweatt JD. 2009. Mechanisms of memory, 2nd ed. Academic Press, London.

Tam S. 2014. Expression of long-term memory after training with inedible food in Aplysia: modification of fast synaptic connections from buccal ganglia mechanoafferents to B4, but not to B31/B32. Program No. 600.01/D43. Neuroscience Meeting Planner. Society for Neuroscience, Washington, DC.

Teyke T, Weiss KR, Kupfemann I. 1990. An identified neuron (CPR) evokes neuronal responses reflecting food arousal in Aplysia. Science 247: 8587.

Warman EN, Chiel HJ. 1995. A new technique for chronic single-unit extracellular recording in freely behaving animals using pipette electrodes. J Neurosci Methods 57: 161-169. doi:10.1016/0165-0270(94) 00144-6

Weiss KR, Cohen JL, Kupfermann I. 1978. Modulatory control of buccal musculature by a serotonergic neuron (metacerebral cell) in Aplysia. J Neurophysiol 41: 181-203. doi:10.1152/jn.1978.41.1.181

Weiss KR, Chiel HJ, Koch U, Kupfermann I. 1986. Activity of an identified histaminergic neuron, and its possible role in arousal of feeding behavior in semi-intact Aplysia. J Neurosci 6: 2403-2415. doi:10.1523/ JNEUROSCI.06-08-02403.1986

Weiss KR, Brezina V, Cropper EC, Heierhorst J, Hooper SL, Probst WC, Rosen SC, Vilim FS, Kupfermann I. 1993. Physiology and biochemistry of peptidergic cotransmission in Aplysia. J Physiol Paris 87: 141-151. doi:10.1016/0928-4257(93)90025-O

Wenning A, Norris BJ, Doloc-Mihu A, Calabrese RL. 2014. Variation in motor output and motor performance in a centrally generated motor pattern. J Neurophysiol 112: 95-109. doi:10.1152/jn.00856.2013

Wentzell MM, Martínez-Rubio C, Miller MW, Murphy AD. 2009. Comparative neurobiology of feeding in the opisthobranch sea slug, Aplysia, and the pulmonate snail, Helisoma: evolutionary considerations. Brain Behav Evol 74: 219-230. doi:10.1159/000258668

Wu JS, Wang N, Siniscalchi MJ, Perkins MH, Zheng YT, Yu W, Chen SA, Jia RN, Gu JW, Qian YQ, et al. 2014. Complementary interactions between command-like interneurons that function to activate and specify motor programs. J Neurosci 34: 6510-6521. doi:10.1523/ JNEUROSCI.5094-13.2014

Ye H, Morton DW, Chiel HJ. 2006a. Neuromechanics of coordination during swallowing in Aplysia californica. J Neurosci 26: 1470-1485. doi:10.1523/JNEUROSCI.3691-05.2006

Ye H, Morton DW, Chiel HJ. 2006b. Neuromechanics of multifunctionality during rejection in Aplysia californica. J Neurosci 26: 10743-10755. doi:10.1523/JNEUROSCI.3143-06.2006

Received November 28, 2018; accepted in revised form March 12, 2019. 


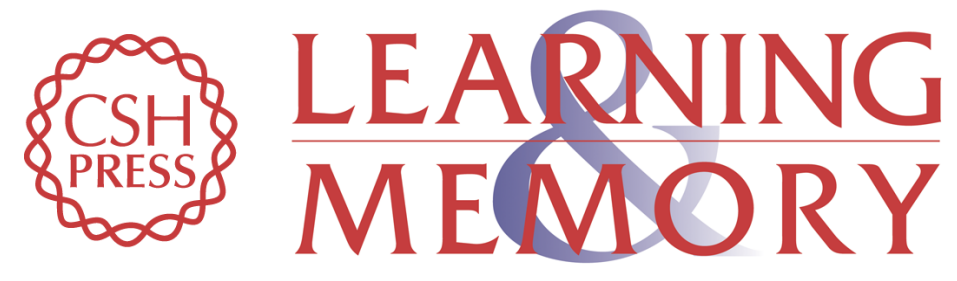

\section{Successful and unsuccessful attempts to swallow in a reduced Aplysia preparation regulate feeding responses and produce memory at different neural sites}

Jeffrey M. McManus, Hillel J. Chiel and Abraham J. Susswein

Learn. Mem. 2019, 26:

Access the most recent version at doi:10.1101//m.048983.118

\section{Supplemental http://learnmem.cshlp.org/content/suppl/2019/04/15/26.5.151.DC1 \\ Material}

References This article cites 86 articles, 39 of which can be accessed free at: http://learnmem.cshlp.org/content/26/5/151.full.html\#ref-list-1

Creative This article is distributed exclusively by Cold Spring Harbor Laboratory Press for the Commons first 12 months after the full-issue publication date (see License http://learnmem.cshlp.org/site/misc/terms.xhtml). After 12 months, it is available under a Creative Commons License (Attribution-NonCommercial 4.0 International), as described at http://creativecommons.org/licenses/by-nc/4.0/.

Email Alerting Receive free email alerts when new articles cite this article - sign up in the box at the Service top right corner of the article or click here. 